Review Article

\title{
A Critical Review of Stall Control Techniques in Industrial Fans
}

\author{
Stefano Bianchi, ${ }^{1}$ Alessandro Corsini, ${ }^{1}$ Anthony G. Sheard, ${ }^{2}$ and Cecilia Tortora ${ }^{1}$ \\ ${ }^{1}$ Dipartimento di Ingegneria Meccanica e Aerospaziale, Sapienza Università di Roma, Via Eudossiana 18, Rome, Italy \\ ${ }^{2}$ Fläkt Woods Limited, Axial Way, Colchester, Essex CO4 5ZD, UK
}

Correspondence should be addressed to Anthony G. Sheard; geoff.sheard@flaktwoods.com

Received 30 March 2013; Accepted 24 April 2013

Academic Editors: J. Clayton, J. Hu, J.-I. Jang, J. Seok, and D. Zhou

Copyright (C) 2013 Stefano Bianchi et al. This is an open access article distributed under the Creative Commons Attribution License, which permits unrestricted use, distribution, and reproduction in any medium, provided the original work is properly cited.

\begin{abstract}
This paper reviews modelling and interpretation advances of industrial fan stall phenomena, related stall detection methods, and control technologies. Competing theories have helped engineers refine fan stability and control technology. With the development of these theories, three major issues have emerged. In this paper, we first consider the interplay between aerodynamic perturbations and instability inception. An understanding of the key physical phenomena that occurs with stall inception is critical to alleviate stall by design or through active or passive control methods. We then review the use of passive and active control strategies to improve fan stability. Whilst historically compressor design engineers have used passive control techniques, recent technologies have prompted them to install high-response stall detection and control systems that provide industrial fan designers with new insight into how they may detect and control stall. Finally, the paper reviews the methods and prospects for early stall detection to complement control systems with a warning capability. Engineers may use an effective real-time stall warning system to extend a fan's operating range by allowing it to operate safely at a reduced stall margin. This may also enable the fan to operate in service at a more efficient point on its characteristic.
\end{abstract}

\section{Introduction}

When a single fan operates in isolation the unstable aerodynamic condition, which we refer to as "stall" occurs at low flow rates. This type of stall varies according to fan type but is most severe in axial fans, forward-curved centrifugal fans, and backward-inclined centrifugal fans [1]. Fan stall occurs as the fan reaches its stable operating range limit. This happens when the pressure rise across a fan increases to the fan's pressure developing limit and the flow velocity though the fan reduces to the point at which it first falls to zero and then reverses. As the flow through a fan reverses, it separates from the fan blades with the turbulence that occurs with the separated flow buffeting the fan blades. This aerodynamic buffeting induces an increase in unsteady stress within the blades that can result in mechanical failure.

As a fan approaches stall, the separated flow initially occurs with one blade passage. Stall in one blade passage increases the aerodynamic blade loading on the adjacent blade passage, with a consequence that the "stall cell" moves to the next blade passage. This results in a cascading effect as a stall cell jumps from blade passage to blade passage. The shape of and distance between fan blades affect how the stall impacts fan performance with more highly aerodynamic loaded blade designs suffering a more severe reduction in performance during stall than lightly loaded designs. Centrifugal fans with radial blades show little change in performance in the event of stall. Radial-blade centrifugal fans do not rely on air passing through the fan and travel perpendicular to the centrifugal force which fan impeller rotation induces. As a result, stall is less of an issue in centrifugal fans generally than it is in axial fans.

Axial fans are particularly vulnerable to stall. Industrial fan manufacturers do not recommend axial fans for use in applications that require widely varying flow requirements unless a means of keeping flow rates above the stall point is available. Industrial fan manufacturers use proprietary antistall devices to control the flow in the axial fans' tip region. These anti-stall devices have the effect of stabilising the fan's performance. This eliminates the drop in fan performance at the point where it would have stalled without the anti-stall device, with the fan exhibiting a continuously rising pressure characteristic back to zero flow. This fan stabilisation is at 
the expense of fan efficiency, which typically reduces between 2 and 5 per cent with the presence of an anti-stall device. With an increasing focus on energy efficiency, anti-stall devices are becoming progressively less acceptable as industrial fan manufacturers strive to meet increasingly demanding minimum efficiency targets.

Historically, manufacturers have utilised anti-stall devices where a fan operates in conditions that may result in the fan stalling. However, application in which engineers do not expect the fan to stall can still result in stall. A fan can stall as a result of fan blade erosion or fouling or a significant increase in system pressure as a consequence of filters clogging. Additionally, a classical cause of industrial fans stalling is running them in parallel. When in parallel operation, one fan starting or stopping as others operate will inevitably result in the fan stalling during its starting and stopping transient. Consequently, poor fan maintenance, the blockage of filters within the system, or inappropriate control system programming can all result in fan stall.

A practice that engineers habitually employ in an attempt to avoid fan stall is oversizing of industrial fans for their application. System design engineers classically apply a safety factor to a fan's operating point when specifying industrial fans. Each engineer involved in the system's design adds his or her own safety factor. The result is that when finally installed, a fan operates on its characteristic far to the left of its optimum operating point. This lowers operating efficiency, with fans capable of achieving 80 per cent efficiency at their optimum operating point and frequently achieving less than 60 per cent when installed.

The European Union Regulation 327 became legally binding on January 1, 2013. This sets the minimum Fan and Motor Efficiency Grades (FMEGs) for industrial fans. The 2013 minimum fan and motor efficiency grades have resulted in approximately 33 per cent of fans sold before January 1 , 2013, now being illegal within Europe as a consequence of not meeting the minimum fan and motor efficiency grade for their application. The European Union will raise minimum fan and motor efficiency grades on January 1, 2015. In the USA, the Department of Energy has been monitoring activity within the European Union. On February 1, 2013, the US federal government published a framework document in the Federal Register. This outlined the intended approach to fan regulation that aims to eliminate inefficient fans within the USA by 2019. The industrial fan community widely anticipates that the Department of Energy will adopt the same approach as the European Union, increasing the minimum allowable fan and motor efficiency within three years of introducing the initial 2019 targets. In practice, Asian countries take their lead on industry regulation from either Europe or the USA and with both now regulating, or declaring intent to do so; it is likely that Asian countries will do the same. Consequently, we may expect that over the next decade minimum fan or fan and motor efficiencies worldwide will first become mandatory, and second increase over time.

Given today's regulatory environment it is reasonable to assume that the pressure on design engineers will increase to develop fans with high peak efficiency. The practice of oversizing fans and fitting anti-stall devices will become progressively less acceptable as a consequence of the negative impact on fan efficiency. The result of specifying a fan such that it operates closer to its peak efficiency point when installed will increase the probability that the fan may stall. The peak efficiency operating point is invariably close to the fan's stability limits, and consequently erosion, fouling or filter clogging are more likely to result in stall. Therefore, the design of inherently "stall tolerant" fans, and development of a stall detection system for in-service use are becoming a rising priority for the industrial fan community.

Researchers have not systematically studied industrial fan in-service performance. However, advanced instrumentation and field testing can play a role in establishing where industrial fans actually operate on their characteristic and in those applications where a fan is prone to stall, assist in the verification and refinement of stall control techniques. Thus, it is not enough to focus on the development of improved design-point performance. Researchers must develop a more complete picture of the challenges that occur with different industrial fan applications if they are to gain an insight into how they may improve fan efficiency without inadvertently producing fan designs more likely to stall in real world applications. This paper describes some of the competing perspectives on the physics that underpin fan aerodynamic stability and how knowledge of that physics can facilitate new industrial fan technology development.

\section{Stall and Surge Dynamics in Axial Compressors and Fans}

Predicting the conditions under which an aerodynamic instability will occur should be a standard part of the industrial fan design process. Over decades researchers have studied different forms of aerodynamic instability. Many studies have clarified the problem of axial flow compressor rotating stall, focusing on multistage machines [2-4]. Emmons et al's [5] earlier work was one of the first attempts to describe the mechanism underlying stall propagation. In general, two primary aerodynamic instabilities occur in decelerating rotors: (i) "rotating stall" in which regions of reversed flow occur locally; and (ii) "surge" in which periodic backflow over the entire annulus results in violent oscillations in the compression system [6]. Both forms of aerodynamic instability place mechanical stress on the rotors which can eventually lead to mechanical failure. Those researchers who have studied the subject report that strain gauge measurements on axial compressors indicate bending stress in blades exceed those measured during stable operation by a factor of five under rotating stall conditions [7]. Increasing bending stresses by a factor of five result in blade fatigue and consequently blade failure. The blade failure may occur whilst the fan operates under rotating stall conditions, but more usually does not. Typically, the fan's operation under rotating stall conditions results in initiating a fatigue crack. Once initiated, a fatigue crack may propagate under the influence of the bending stresses induced in the fan blades by normal operation. Consequently, a fan may fail due to fatigue days, weeks, or even months after operating under rotating stall conditions. By contrast, a surge can lead to the bending stress that 
increases to a magnitude at which mechanical failure occurs during the surge event itself.

Rotating stall is a progressive phenomenon, and, at least, initially does not necessarily result in the breakdown of a fan's pressure developing capability. Rotating stall, at least for axial machines [8], constitutes inception of the more severe flow instability, surge. Surge is a self-excited cyclic phenomenon, which affects the compression system as a whole. Large amplitude pressure rise and annulus averaged mass flow fluctuations characterise surge. It develops where a compressors constant speed pressure rise-volume flow characteristic line has an abrupt change in slope [8]. In Wo and Bons [9], the authors studied compressor performance, and reported experimental results that enabled them to conclude that a compressor's pressure rise-flow characteristic includes a region with positive slope. This indicates stall occurrence. Consequently, surge onset is dependent on both the compressor's characteristic and the system's characteristics into which it discharges.

Although we may regard rotating stall as a precursor to surge, the two constitute different aerodynamic phenomenon. The average flow during rotating stall is steady in time, but is circumferentially nonuniform. During a surge the flow is unsteady, but circumferentially uniform. It is as a consequence of a steady average flow with time that rotating stall may be localised within one or more of a compressor's stages. This has little or no effect on the system within which a manufacturer installs it. In contrast, the unsteady flow associated with surge impacts not only on the compressor, but the entire compression system.

Rotating stall and surge are distinctly different aerodynamic phenomenon but do share a common characteristic. We may regard both as the compression system's natural oscillatory modes [10-16]. Researchers are still debating whether rotating stall can result in centrifugal and single stage axial compressor mechanical failure, or if only surge can result in mechanical damage in these classes of rotating machines. The debate is inconclusive, and within the community that has studied rotating stall in centrifugal and single stage axial compressors there is disagreement as to the importance of rotating stall. This paper focuses on industrial fan technology rather than compressor technology, where researchers agree that rotating stall does result in mechanical damage and ultimately failure. Although a review of the effect of rotating stall in centrifugal and single stage axial compressors is beyond the scope of this paper, we review the extant literature within the context of its applicability to industrial fans. Our aim is to apply to the study of industrial fans the research from those academics and practitioners who focus on centrifugal and single stage axial compressors.

\section{The Aerodynamics of Stall}

For multi-stage axial compressors, rotating stall occurs at low shaft speeds and surge occurs at high speeds [8, 17-27]. The distinction between low and high shaft speeds is a distinction between the ratio of pressure forces and flow momentum, which increase with increasing rotor speed. Recovering a multi-stage axial compressor from rotating stall is more difficult than recovery from surge [28]. Rotating stall is not a single phenomenon, but rather two distinctly different phenomena [29].

(i) Part span: where there is only a restricted blade passage region.

(ii) Full span: the blade passage region is even smaller than in the case of part-span.

(iii) Small scale: where a small part of the annular flow path is blocked.

(iv) Large scale: where a large part of the annular flow path is blocked.

Surge has a more complex typology than rotating stall. We can distinguish at least four different surge categories with respect to flow and pressure fluctuations $[8,17,30]$.

(i) Mild surge: a phenomenon associated with small pressure fluctuations and a periodicity governed by the Helmholtz resonance frequency. Flow reversal does not occur.

(ii) Classic surge: a phenomenon associated with larger oscillations at a lower frequency than mild surge, also with no flow reversal. High frequency oscillations may also be present as the surge dynamics are nonlinear and introduce higher harmonics.

(iii) Modified surge: a phenomenon associated with the entire annulus flow fluctuating in the axial direction, with rotating stall superimposed. This results in unsteady and non-axisymmetric flow. Modified surge is a mix of rotating stall and classic surge.

(iv) Deep surge: a phenomenon associated with a more severe version of classic surge, where flow reversal occurs over the entire annulus.

When we consider an industrial fan's characteristics, we see that for a fixed blade angle and fan speed, as pressure across the fan reduces, flow increases. Bianchi et al. [31] studied the characteristics of an industrial fan, identifying the stable region over which reducing pressure results in increasing flow. In addition to the fan characteristic's stable region Bianchi et al. [31] characterised the fans unstable region, (Figure 1).

The resistance of an aerodynamic system increases with the square of the flow velocity through the system. Generating velocity, fan pressure increases with the square of velocity. If the required pressure is beyond the fan's peak pressure developing capability, the fan moves from the stable to unstable region. As a fan moves into the unstable region, both pressure and flow reduce. As the flow reduces, the required pressure to drive the flow through the system falls with the square root of speed. This results in the fan moving back into the stable region. As the fan operation stabilises, it generates additional flow and correspondingly, increasing system pressure until it drives into the unstable region again. This cyclic behaviour results in a hunting action that generates a characteristic sound similar to breathing.

An industrial fan's cyclic behaviour in surge may occur as a consequence of poor system design or leakage within the 


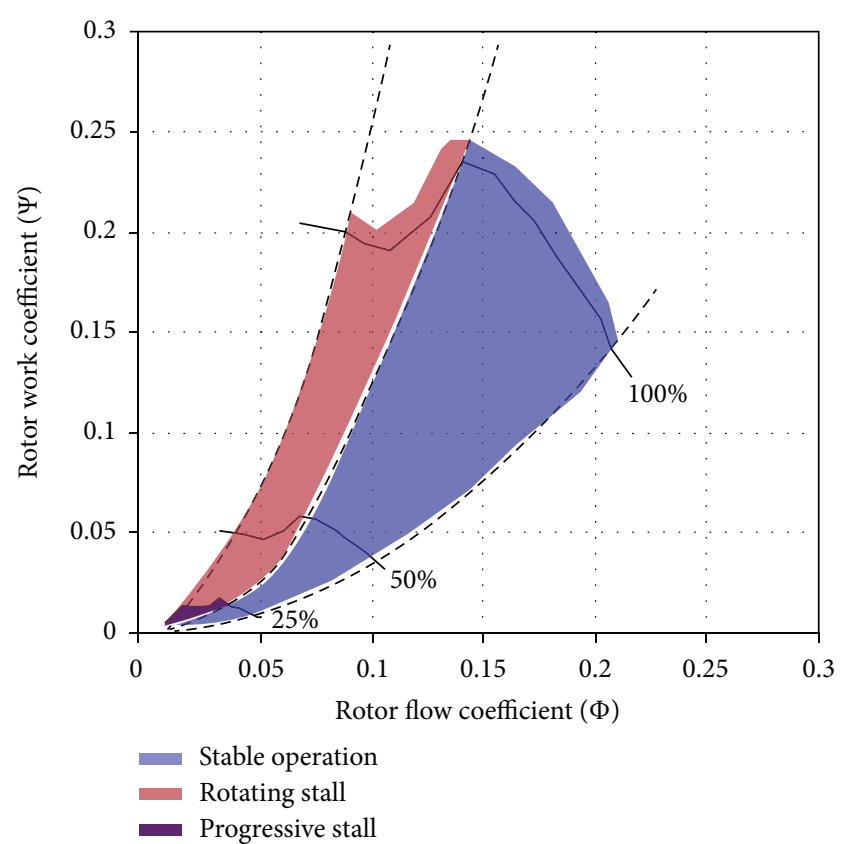

FIGURE 1: Regions of stable fan operation, rotating stall and progressive stall identified by Bianchi et al. [31] for an axial tunnel ventilation fan operating at 100 per cent, 50 per cent and 25 per cent fan design speed.

system. Classically, the systems into which engineers apply industrial fans include multiple branches with dampers fitted to enable flow to be directed down different branches at various times. If a branch in the system includes a damper that becomes stuck open, then this branch may result in the system becoming unbalanced, with a consequence that the fan may drive itself into an unstable region. In cases where the fan is operating primarily within the stable region with only occasional excursions into the unstable region, the fan can operate for extended periods of time without mechanical failure. In severe cases the fan motor will overload and overheat, and if the cyclic behaviour continues, fan blade mechanical failure will occur.

3.1. Stall Inception. The first challenge in attempting to identify appropriate approaches to stall control in industrial fans is to develop a fundamental understanding of the key physical phenomena which drive stall. The focus of any characterisation must be the stall inception process, as opposed to the characterisation of fully developed stall. Many researchers have characterised fully developed stall, with the research in the extant literature primarily focused on axial compressors. For a comprehensive review see Day and Cumpsty [3]. When considering the key physical phenomenon that drive stall in industrial fans, it is helpful to consider an industrial fans' tendency to exhibit cyclic behaviour as it moves from the stable to unstable region. A functional description of the processes at play during this cycle behaviour can provide the necessary insight to conceptualise, specify, and design a stall detection system.
Studying a subset of the published research scholars have conducted on industrial fans and in compressor research facilities facilitates the identification of key processes at play as an industrial fan moves from the stable to unstable region of its characteristic. Results that researchers have obtained in both types of rigs reproduce the physical phenomena at play within full scale compressors. A review of the results in low speed fan and scaled compressor facilities indicates that there is a hierarchy of possible stall inception mechanisms, starting with those that occur with low speed compressors and moving on to those that occur with multi-stage high speed compressors.

When we study the literature on low speed fan and scaled compressor facilities, it is apparent that two competing perspectives dominate the debate on stall inception and the physical mechanisms at play within rotating machinery. The first perspective focuses on long wavelength processes, or waves which span at least several blade pitches circumferentially. These waves constitute the primary physical process that determines compressor stability. The competing perspective focuses on short length scale events that are localised within one to four blade passages. Researchers consider these short length scale events as primarily responsible for stall inception. Although physical explanations of short length scale event significance dates back to Emmons, the concept that they may occur with stall inception is relatively new [5].

Several studies have suggested that some tip flow features in both compressors, low- and high-speed axial fans are directly responsible for generating short wavelength disturbances. The researchers studying short wavelength disturbances refer to them as "spikes" or "pips" that are responsible for localised part-span stall cells [32-35]. The stall cell's spikelike inception in a single stage is clearly evident in data that researchers obtained from a model fan [36]. We can see the spike-like inception at 28.5 seconds, Figure 2, with the flow then returning to its steady state condition for half a second before becoming unsteady at 29 seconds. Researchers studying stall inception mechanisms in industrial fans have correlated the spike-like inceptions with a change in fan acoustic emissions [37]. Other scholars studying the link between stall inception and acoustic emissions have utilised arrays of azimuthally distributed probes in an attempt to link the rotating unsteady pressure signals that they have measured in centrifugal pumps and compressors to their acoustic signatures [38,39]. Kameier and Neise [40] and Bianchi and co-authors [31, 41] also studied the link between stall inception and acoustic emissions by establishing a link between tip-clearance noise and associated blade-tip flow instabilities in axial turbomachinery.

3.2. Stall Development. There is a general consensus among researchers that stall is an instability phenomenon, local to the fan stage or rotor, in which a circumferentially uniform flow pattern ultimately results in completely blocking the annulus. As the fan blades become progressively more highly loaded, the stall commences with a "spike like" event and evolves into a rotating stall. The rotating stall classically evolves into a full stall or surge if there is a high enough system back pressure. A local stagnant flow region appears when 

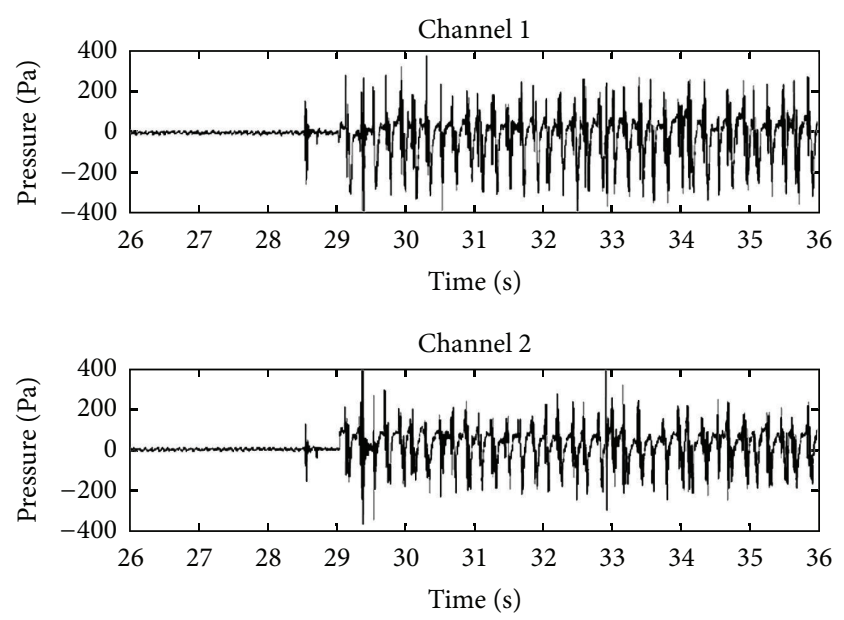

FIGURE 2: Data recorded from a pair of circumferentially offset high frequency response pressure transducers located over the blades of a $1250 \mathrm{~mm}$ diameter model of a variable pitch in motion induced draft fan. From 26 to 28.5, the fan is operating in the stable region of its characteristic. We can observe a spike-like feature at 28.5 seconds that is characteristic of stall inception. From 29 to 36 seconds the variation in pressure is associated with the fan's stalled operation [36].

the flow stalls. The regions propagate in the same direction as the blade rotation. This results in the stall region rotating around the annular flow path at a fraction of the rotor speed. The speed with which the stall rotates is typically between one-fifth and half of the rotor speed for fully developed stall. Initially, rotating stall cells rotate faster [29].

In reviewing rotating stall evolution, Cumpsty [37] noted that the drop in overall performance can occur as a so-called "progressive stall" or an "abrupt stall." Engineers usually associate the former with a part-span stall, which results in a small performance drop; whereas, they associate the latter with a full-span stall and a large drop in performance. Notably, the part-span rotating stall occurs typically in single blade rows [37] and usually leads to more complex disturbances in single-rotor or stage machines than in multi-stage compressors [4].

3.3. Mechanical Failure. Engineers have used strain gauge measurements on axial compressors [42] to measure bending stress in vanes that exceed stable operation by a factor of five under "rotating stall" conditions. Figure 3 illustrates an example of an industrial fan blade's mechanical failure that occurs with the unsteady mechanical loading that resulted from the fan stalling. In this example, stall resulted in a blade fatigue failure after operating approximately ten hours in a stalled condition. If this fan had been able to generate a backpressure high enough to result in surge, the bending stress's heightening magnitude would have been enough to cause a mechanical failure during the surge event itself.

An additional issue that industrial fan designers face is new legislation that governs the design of industrial fans that are intended for duel use. In this context, duel use refers to a fan use to both ventilate a tunnel or building during

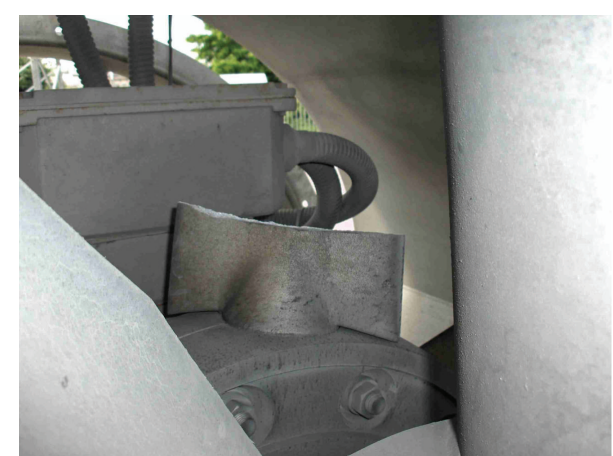

FIGURE 3: An example of a fan blade with a blade mechanical failure at the root aerofoil interface. This fan operated for approximately ten hours in a stalled condition before the mechanical failure [46].

normal operation and clear smoke from escape routes in the event of a fire. Within the European Union it is a legal requirement to supply fans that are certified in accordance with EN 12101-3 requirements [43, 44], and outside the European Union the same requirements defined in EN 121013 are embodied within ISO 21927-3 [44, 45]. When extracting hot gas and smoke, an industrial fan's aluminium blades will grow thermally at a faster rate than the steel casing within which they rotate. Consequently, if the blades are not to touch the casing in the event of a fire the ambient blade tip-to-casing gap must be larger than would be the case if the fan were for ambient use only [42]. A consequence of increasing the blade tip-to-casing gap is typically a 20 per cent reduction in the fan's pressure developing capability. Fan designers frequently underestimate the impact of increasing the blade tip-to-casing gap on an industrial fan's pressure developing capability. A result of underestimating this reduction is that fans intended for dual-use operation are typically more prone to stall in service [46].

A particular feature of the environment within which industrial fans in tunnel ventilation applications operate is the pressure pulses that occur with trains moving through a tunnel. Pressure pulses can be up to \pm 50 per cent of the overall tunnel ventilation fan's work coefficient. Such pressure pulses drive the tunnel ventilation fan first up and then down its characteristic operating range [47]. To ensure that the tunnel ventilation fan continues to operate in an aerodynamically stable manner during this pressure transient, the tunnel ventilation system designer must incorporate sufficient margin to ensure that the tunnel ventilation fan does not stall due to the pressure pulses that occur with a train approaching and then moving away from a ventilation shaft.

A tunnel ventilation fan's propensity to stall under the influence of a pressure pulse is compounded when one operates at part speed. It is increasingly common to operate tunnel ventilation fans at part speed. Typically, the need for tunnel ventilation reduces at night, and therefore, one can achieve adequate cooling at a lower fan speed, and consequently at a lower operating cost. Although one may operate the tunnel ventilation fans at a lower speed, the speed of trains travelling within the tunnel remains constant, and therefore the pressure pulse magnitudes to which tunnel 
ventilation fans are subjected also remains constant. When a tunnel ventilation fan operates at 50 per cent speed, its pressure developing capability reduces by a factor of four. Consequently, a pressure pulse that could be accommodated at full speed will almost certainly drive the same tunnel ventilation fan into stall at 50 per cent speed.

As tunnel ventilation fan speed reduces, with a constant pressure pulse associated with trains passing the ventilation shaft within which the fan is located, there will be a critical speed at which a fan operating in supply mode stalls as the train approaches, or if the fan is operating in extract mode stalls as the train departs. Aerodynamic stall results in a significant increase in the unsteady forces applied to the fan blades. However, as the pressure pulse is transient the fan is not operated in a stalled condition for an extended period of time. Consequently the unsteady aerodynamic forces do not result in an immediate mechanical failure. However as a tunnel ventilation fan may be subjected to many pressure pulses each day, over time the cumulative effect of driving transiently into stall is to initiate a fatigue crack in one blade that then goes on to grow during stable operation until the blade mechanically fails.

We may conceptualise the impact of both positive and negative pressure pulses on a tunnel ventilation fan's operating point by referring to Figure 4 . This provides an insight into how a fan adapts to a pressure pulse, with the duty point shifting up and down the fan characteristic under the influence of $\mathrm{a}+1000 \mathrm{~Pa}$ and $-1000 \mathrm{~Pa}$ pressure pulse. It is custom and practice within the industrial fan community to assume that a pressure pulse may be modeled by shifting the system curve up and down by the magnitude of the pressure pulse. In Figure 4 the + and -1000 Pa pressure pulse system curves are generated by shifting the system curve up and down $1000 \mathrm{~Pa}$, respectively. Under the influence of a positive pressure pulse the fan operating point is assumed to shift from the fan duty point (black circle, Figure 4 ) to the point where the fan characteristic intersections the +1000 system curve (black square, Figure 4). Under the influence of a negative pressure pulse the fan operating point is assumed to shift from the fan duty point to the point where the fan characteristic intersects the -1000 system curve (black diamond, Figure 4). In doing so the fan is assumed to respond to a pressure pulse as if the change in pressure associated with the pressure pulse is slow in comparison to the reaction time of the fan.

Recent research [47] suggests that tunnel ventilation fans do not respond to a pressure pulse as if the change in pressure associated with the pressure pulse is slow in comparison to the reaction time of the fan. The interaction between changing pressure in a tunnel and the flow-field around fan blades is both transient and complex. When a pressure pulse within a tunnel is studied, it may be conceptualised as a change in volume flow rate though the fan. Unsteady computational results for a tunnel ventilation fan operating in extract mode [47] indicate that the impact of a train approaching the ventilation shaft within which a tunnel ventilation fan is situated is to unload the fan. The result is that the fan duty point shifts almost instantaneously to a lower pressure (blue circle, Figure 4). As a train passes the ventilation shaft a tunnel ventilation shaft with the tunnel ventilation fan operating in

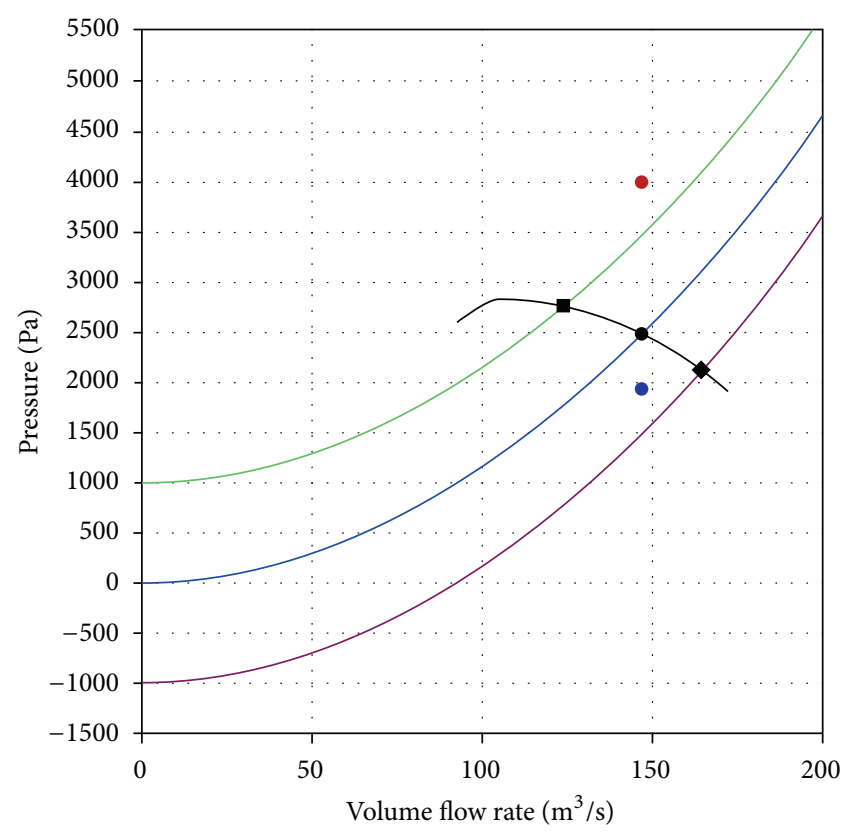

- Unsteady computation, peak pressure across fan in extract mode with train departing

- Fan duty point with +1000 Pa pressure pulse

- Fan duty point

- Fan duty point with -1000 Pa pressure pulse

- Unsteady computation, peak pressure across fan in extract mode with train approaching

- Experimental data

+ $+1000 \mathrm{~Pa}$ system curve

_ System curve

- $-1000 \mathrm{~Pa}$ system curve

Figure 4: The effect of a pressure pulse on a tunnel ventilation fan. Industrial fan designers have historically assumed that a fan runs up and down its characteristic in the presence of a pressure pulse (black symbols). Unsteady computational results for both a positive and negative pressure pulse indicate that the fan's operating point departs from its steady state characteristic during the transient associated with a pressure pulse (red and blue symbols). This departure results in unsteady aerodynamic forces increasing by a factor of two compared to those associated with operation of the fan at its duty point [47].

extract mode, the fan is over loaded. The result is that the fan operating point shifts almost instantaneously to a higher pressure (red circle, Figure 4). Significantly the time scales of this shift in operating point (from black circle to red circle and then back to black circle, Figure 4) are so rapid that the fan does not stall [47].

Despite the fan not stalling, unsteady forces on fan blades were shown to double in comparison to those associated with stable operation at the fans duty point [47]. This doubling of unsteady blade forces is significant. Within the industrial fan community designers generally believe that as long as a pressure pulse can be accommodated within the fan's pressure developing capability, as is the case in the example given in Figure 4, there is no mechanical consequence associated with pressure pulses. This is not the case and consequently, if blade 


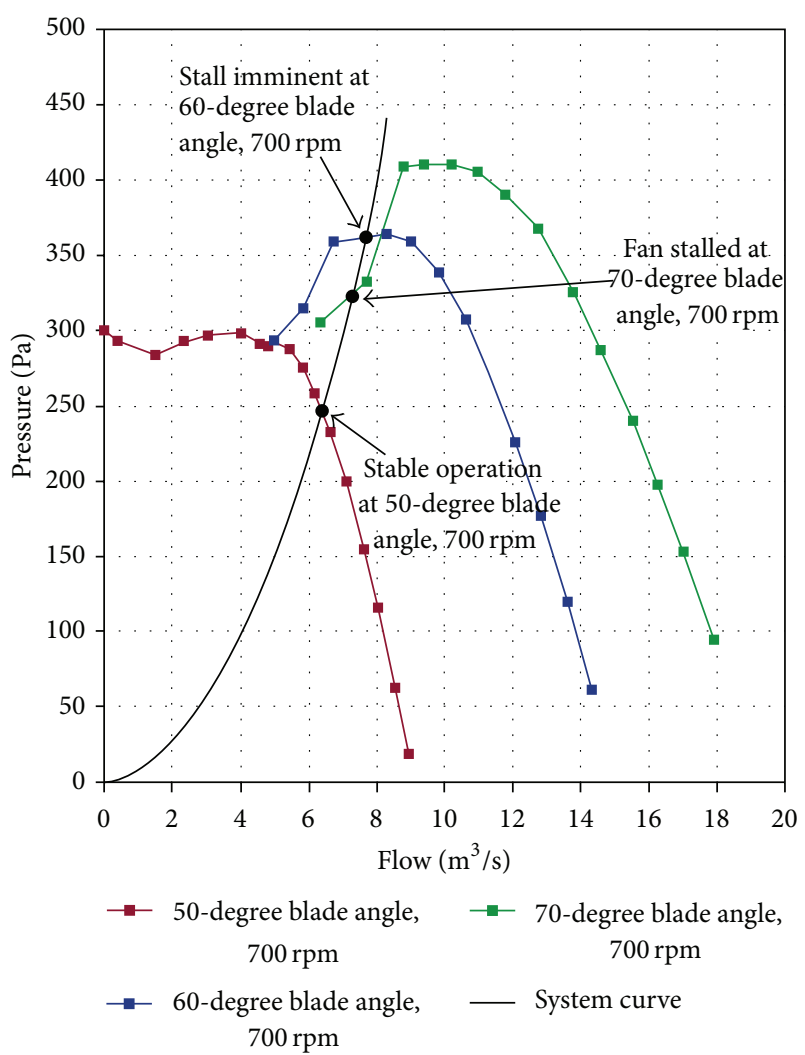

FIGURE 5: Stall recovery using variable pitch in motion (VPIM) blades. Operating points at $70^{\circ}, 60^{\circ}$, and $50^{\circ}$ pitch angle with all data taken at a rotational frequency of $700 \mathrm{rpm}$. At $70^{\circ}$ the fan is operating in a stalled condition, to the left of the characteristics peak pressure. At $60^{\circ}$ the fan remains stalled, with the fan operating just to the left of the peak in its characteristic. At $50^{\circ}$ the fan is operating in the stable part of its characteristic, to the right of the characteristics peak pressure [36].

designs are to avoid in-service mechanical failure, engineers must design them to accommodate the elevated aerodynamic forces that occur with pressure pulses.

\section{Stall Control Techniques}

We typically derive flow control methodologies from an understanding of the relevant mechanisms or processes [48] and we can categorise them according to how one utilises flow control [49]. This can be

\section{(i) active, entailing flow control; or}

(ii) passive, entailing a flow management.

Engineers have successfully applied passive and active stall control techniques into both industrial fan and compressor applications. However, passive stall control techniques are the norm in industrial fan applications and were the norm in compressor applications in the 1950s and 1960s. The drive to improve stability margin has been most intense within the compressor industry, and consequently, that is where the majority of active stall control research effort has taken place over the last two decades.
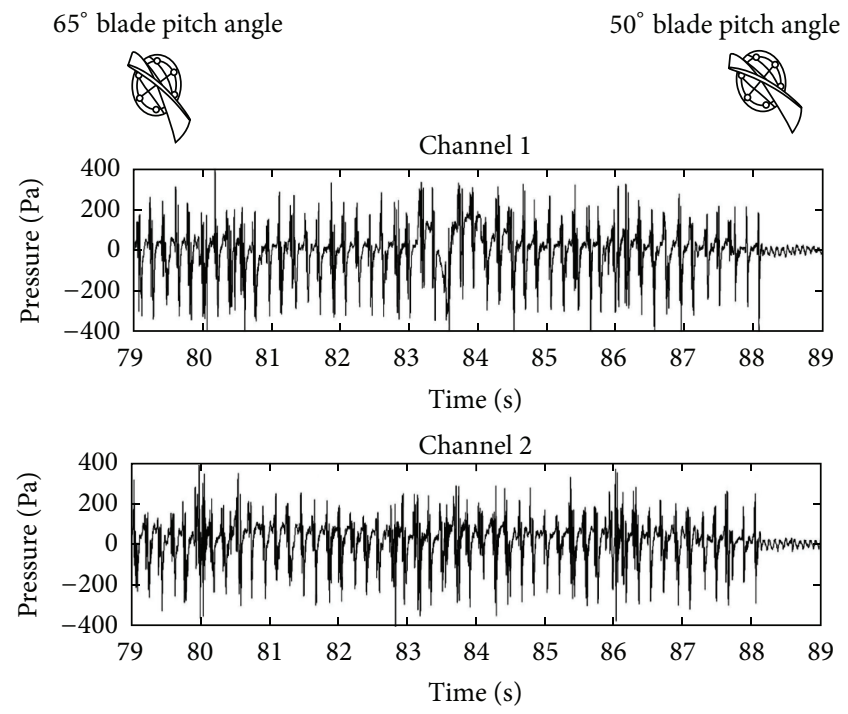

FIGURE 6: Data recorded from a pair of circumferentially offset high frequency response pressure transducers located over the blades of a $1250 \mathrm{~mm}$ diameter model of a variable pitch in motion induced draft fan. Blade angle reduces with increasing time, with the fan finally transitioning from stalled operation to stable operation at 89 seconds, at which time blade angle had reduced from an initial $70^{\circ}$ at 79 seconds to $50^{\circ}$ at 89 seconds [36].

4.1. Active Control Systems. Active control systems monitor the event and its physics by relying on adequate warning or detection schemes in order to achieve the control objective. By contrast, passive control systems modify the flow dynamics in an effort to prevent the stall inception or to reduce the stall. Researchers have traditionally based the passive or preventive control concepts around blade or casing geometry modifications.

4.2. Active: Blade Pitch Control. Rotor pitch control is a technique that engineers mostly use in open rotors such as propellers or wind turbines to reduce the power when the air speed is above an allowable limit. With regards to axial fans, changing the angle formed by the blade's chord perpendicular to the axis direction constitutes a way to recover from stall. Lowering the pitch angle reduces the incidence angle onto the blade and reduces the blade loading. When we consider a variable pitch in motion (VPIM) fan's characteristic, it is apparent as the pitch angle reduces the fan's operating point migrates from the unstable to the stable region of the fans characteristic, Figure 5. It is the movement from the unstable to stable region that allows a reduction in blade angle to constitute a method by which a stall control system may recover a fan from stall. Bianchi et al. [36] studied experimental data from a variable pitch in motion fan as pitch angle reduced, observing that the pressure stabilised after 89 seconds, Figure 6 , with reducing pitch angle. Consequently, a fan that was stalling with a $70^{\circ}$ pitch angle no longer stalls when the pitch angle reduces to $50^{\circ}$.

4.3. Active: Rotational Frequency Control. A change in fan rotational speed does not result in a recovery from 
stall. Assuming that a fan is installed in a system with characteristics that obey the fan laws, a fan that is operating in the unstable region of its characteristic at 100 per cent speed will also be operating in the unstable region of its characteristic at reduced speeds. Therefore, reducing fan speed does not constitute a stall control method. Despite this reservation, reducing fan speed can protect a fan from the mechanical effects associated with operating in the unstable region of its characteristic. The direct mechanical stress in rotating components reduces with the square of speed. Consequently, reducing from 100 per cent to 50 per cent of design fan speed will reduce the direct mechanical stress in rotating components by a factor of four. However, operating a fan in the unstable region of its characteristic results in an increase in alternating stress induced in the fan blades as a consequence of the aerodynamic buffeting associated with stall.

Sheard and Corsini [7] studied the effect of operating a fan in the unstable region of its characteristic at full and part speed. They were faced with a particular problem with the fans supplied for an extension of the Athens Metro. Although the fans met their specification, during the summer when residents close to metro ventilation shaft portals were trying to sleep with their windows open, the noise from portals was loud enough to be problematic. The Athens Metro was asked to reduce night time portal noise emissions. A study of ventilation fan installations indicated that adding additional silencers was not practical. As there were multiple fans installed in each ventilation shaft, with only one required to run at night to supply the required flow of ventilation air, an option was to run multiple fans at reduced speed. Running a fan at reduced speed will reduce fan noise but reduce the flow of ventilation air. Running multiple fans will increase the volume of ventilation air, but as there are now multiple sound sources, the noise generated increases. Critically, the increase in noise associated with multiple sources will be less than the reduction associated with running multiple fans at reduced speed. Consequently, running multiple fans at part speed reduces overall portal noise emissions.

However, the reduction in fan pressure developing capability associated with part-speed operation was potentially problematic. The ventilation fans were subjected to a $500 \mathrm{~Pa}$ pressure pulse each time a train passed the ventilation shaft within which they were installed. When running at partspeed this pressure pulse would result in the ventilation fans driving from the fan characteristic's stable to unstable region each time a train passed the ventilation shaft. Although the ventilation fans would only drive into the unstable region of their characteristic transiently by a pressure pulse, with hundreds of trains passing each ventilation shaft each day, the cumulative effect would be the development of a fatigue crack in a blade followed by a mechanical failure.

Sheard and Corsini [7] studied the tunnel ventilation fan's mechanical performance. They fitted strain gauges to the blades, measuring the unsteady stress associated with operating the fan in both the fan characteristic's stable and unstable region at 100 per cent, 50 per cent, and 25 per cent design speed. In combination with the calculated direct stress in the fan blades at each speed, Sheard and Corsini [7] were able to derive a mechanical safety factor, Table 1 . The results indicated that the tested fan may operate at 100 per cent speed in the stable region of its characteristic with a mechanical safety factor of 2.3. The same fan may also operate at 50 per cent speed in the unstable region of its characteristic with a mechanical safety factor of 2.5. As the safety factor 2.5 is larger than the safety factor 2.3 , we may conclude that one may operate this fan at 50 per cent in the unstable region of its characteristic with less risk of mechanical failure than at 100 per cent speed in the characteristic's stable region. Consequently, reducing fan speed from 100 per cent to 50 per cent speed does not constitute a method of controlling stall, but does constitute a method of protecting the fan from mechanical failure in the event that operating in the fan characteristic's unstable part is unavoidable.

Sheard and Corsini [7] extended their analysis, scaling the studied fans' characteristics from 100 per cent to 90 per cent speed. They observed that by doing so the fans' pressure developing capability reduced to a point where the $500 \mathrm{~Pa}$ pressure pulses to which this fan was subjected in practical application would take the fan to within 5 per cent of the fans' peak pressure developing capability. When Sheard and Corsini [7] scaled the studied fans' characteristics from 50 per cent to 55 per cent speed they concluded that a $500 \mathrm{~Pa}$ pressure pulse would still drive the fan from the stable to unstable region of its characteristic. However the increase in speed resulted in the mechanical safety factor reducing from 2.5 at 50 per cent design speed to 2.0 at 55 per cent design speed. From the above Sheard and Corsini [7] concluded that the tested fan could operate at up to 55 per cent design speed in the unstable region of its characteristic and down to 90 per cent design speed whilst remaining in the characteristic's stable region. The speed range between 55 and 90 per cent design speed was blocked in the fans' variable speed drive, and ensured that the fan only operated at speeds that did not put the fan at risk of mechanical failure under the influence of the pressure pulses.

Industrial fan manufacturers also utilise rotational frequency control to protect ventilation fans from the effect of unforeseen changes in system resistance. As the change in system resistance is unforeseen, it is not possible to predict the time when the change will occur. Bianchi et al. [31] studied a tunnel ventilation fan's stall characteristics using four unsteady pressure probes that they mounted on the fan casing whilst driving the studied fan into stall at 100 per cent, 50 per cent and 25 per cent of its nominal design speed. This allowed Bianchi et al. [31] to study the unsteady pressure signals that occurred with the fan's stable operation when instability was incipient and during stalled operation, Figure 7. Analysing the unsteady pressure signals enabled Bianchi et al. [31] to characterise the fan and identify the fan characteristic's stable and unstable regions at different fan speeds. From this, we may use an unsteady pressure measurement on the fan casing, in combination with the "blocked" speed range, 55 per cent to 90 per cent of design speed for the fan that Sheard and Corsini studied [7], as input for a control algorithm that establishes if a fan is mechanically at risk or may continue to operate without risk of mechanical failure. 
TABLE 1: Safety factors derived from strain gauge data for a fan at full and part speed [7].

\begin{tabular}{lccc}
\hline Fan type & \% design speed & $\begin{array}{c}\text { Normal operating } \\
\text { safety factor }\end{array}$ & $\begin{array}{c}\text { Stalled operating } \\
\text { safety factor }\end{array}$ \\
\hline Plane casing, stalling blade angle & 100 & 2.3 & 0.3 \\
Plane casing, stalling blade angle & 50 & 10.0 & 2.5 \\
Plane casing, stalling blade angle & 25 & 106.0 & 7.3 \\
\hline
\end{tabular}

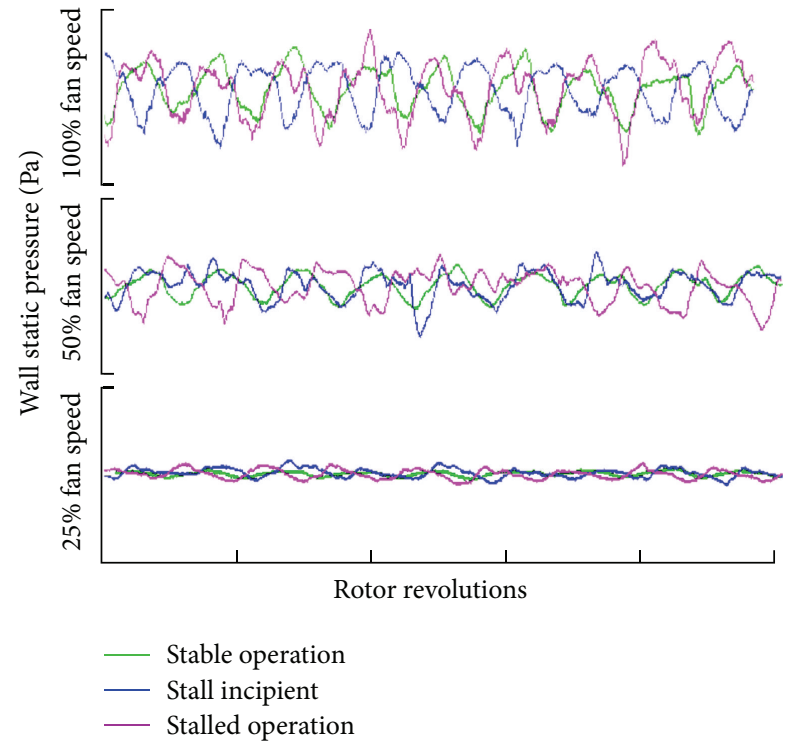

FIGURE 7: Low-pass filtered data $(20 \mathrm{kHz})$ from a high frequency response pressure transducer located over the blades of a tunnel ventilation fan. The authors recorded the data during stable operation (green), when stall was incipient (blue) and during stalled operation (red) at full speed, (a) half-speed (b) and quarter-speed (c) [31].

4.4. Active: Air Injection. Researchers typically associate spike-like pressure pulses with stall inception in single rotor or stage industrial fans and compressors. A stall control technique that is effective in suppressing the spike-like pressure pulses is air injection. Air injection involves injecting high speed jets of air into the blade tip region that induces a transfer of momentum from the jet to the slower moving mainstream flow. The effectiveness of the high speed jets in suppressing the onset of stall is linked to the jets' influence on the tip clearance vortex's evolution and other flow features that occur with the over-tip blade flow.

Researchers have extensively studied air injection. Suder et al. [50] proposed a discrete tip injection technique, and Nie et al. [51] and Lin et al. [52] based their proposal on microair injection. Whilst requiring significant power to drive the associated control system actuation, these control techniques result in 5 to 10 per cent improvement in compressor stall margin. More recently, researchers have studied the underlying flow physics that occur with flow-field excitation in the blade tip-to-casing region using a spatially distributed actuation system to control the blade tip leakage vortex's evolution [53]. The researchers' hypothesis is that controlling the blade tip leakage vortex's evolution will promote the tip vortices' dissipation and therefore will suppress a part of the flow structure involved in spike formation.

A potential advantage of a spatially distributed actuation system to control the blade tip leakage vortex evolution is the low power requirement that occurs with control system actuators. The necessary power requirement to drive a control system's actuators constitutes a loss of efficiency for the industrial fan or compressor to which the control system is fitted. In an effort to minimise the power requirement, Vo et al. [54] proposed the use of acoustic actuation and Corke and Post [55] proposed magnetic actuators. Interest remains high in air injection within the compressor community, with Vo [56] proposing a method to suppress rotating stall inception in multi-stage compressors around the compressor's full circumference, Figure 8. At the time of writing the use of air injection is limited to compressor applications as a consequence of the complexity and cost of the technology. The industrial fan community continues to monitor the compressor community's progress, but currently there is no active research aimed at transferring this technology to industrial fans.

4.5. Active: Bleed Valves. Researchers have tested stall control with bleed valve actuation on a small scale with compressors at low speed $[57,58]$. The bleed valve opens to suppress the onset of stall. The technique aims to maintain the average flow through a compressor above the compressor's critical flow, below which the compressor blades will stall. The operator maintains average flow using bleed air from the compressor discharge that increases the flow through the compressor's lower pressure stages.

Prasad et al. [57] have presented two schemes for using bleed valve actuation: bleed air back into the compressor inlet and bleed air back into a recirculation plenum inlet. In the former, the bleed air does not affect the flow through the inlet; however, the bleed does decrease the flow to the combustor. In the latter, the flow into the combustor is equal to the inlet flow with the re-circulated air reducing the compressor load. The second scheme is more effective as bleed recirculation delays the onset of rotating stall and the delay increases with the magnitude of recirculation. Recirculation reduces flow into the combustor by altering the compressor's operating point, and consequently, an operator should not use recirculation continuously, but only when stall is imminent.

4.6. Passive Control Systems. Researchers base passive approaches to stall control on techniques that modify the flow field in the blade tip-to-casing region. Passive approaches date back to the 1950s, when researchers first utilised casing treatments in axial compressors. Skewed slots and grooves 


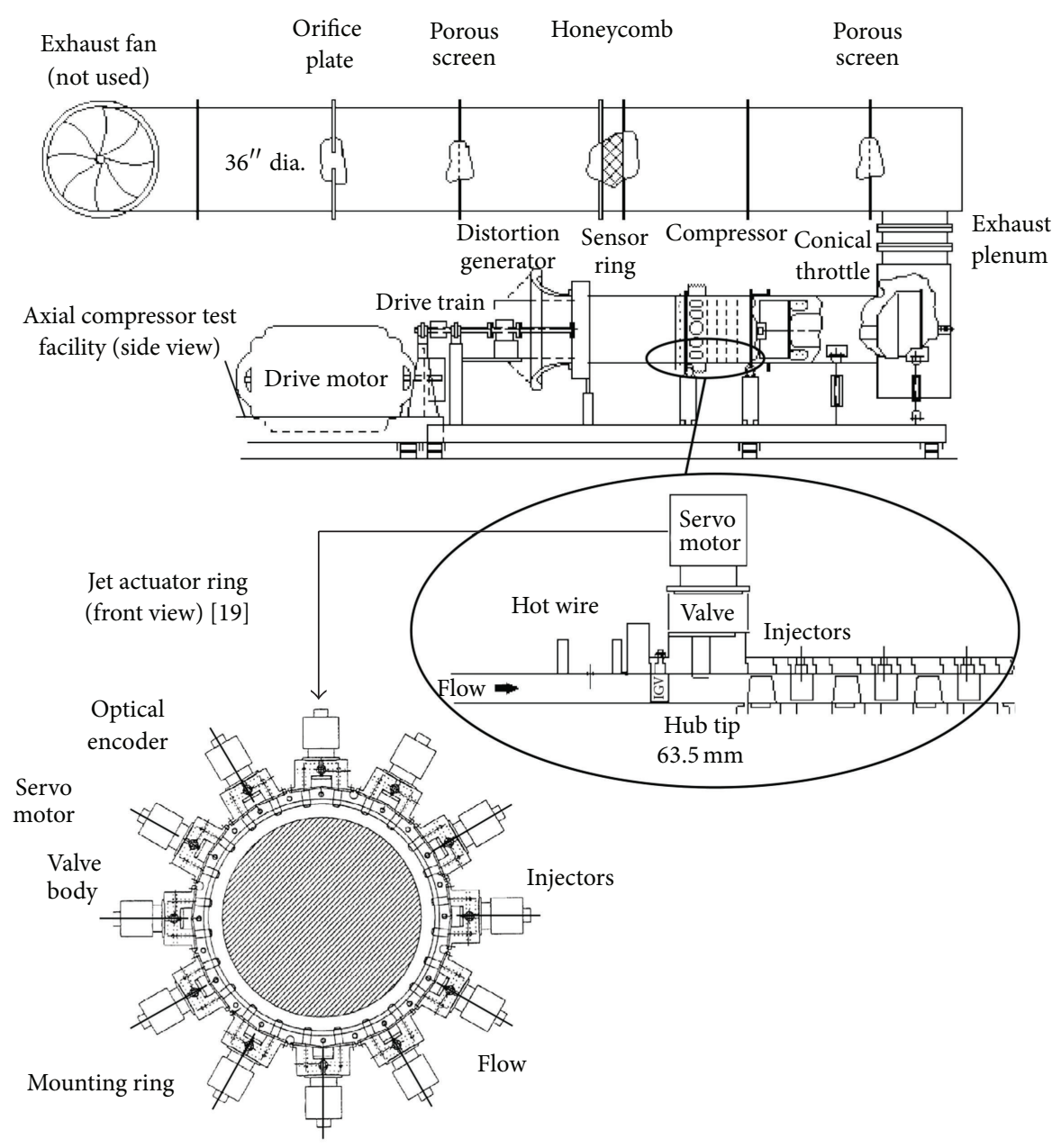

FIgURE 8: The Massachusetts Institute of Technology (MIT) low-speed three-stage axial compressor test facility with jet actuation [56].

cut into the casing above the rotor improved stall-margin, with grooves both improving stall-margin and having the lowest impact on compressor efficiency [59]. The relatively low cost of passive approaches has resulted in industrial fan manufacturers historically favouring them. Consequently, whilst the compressor community today utilises primarily active control approaches, industrial fan manufacturers are still developing and refining passive approaches.

4.7. Passive: Stabilisation Rings. Industrial fan manufacturers have historically favoured the stabilisation ring, fitted to the fan casing, as the preferred antistall device. As an axial fan approaches stall, the flow velocity through the fan reduces and the axial fan blades increasingly act as a centrifugal fan impeller. Although antistall devices have evolved, their most common present day embodiment consists of a stabilisation ring placed around a fan casing immediately upstream of the fan blades' leading edge, Figure 9. As an axial fan approaches stall, the flow velocity through the fan reduces and the flow progressively centrifuges towards the blade tips. At a critical pressure across the fan, the flow velocity falls to zero, and the flow in the blade tip region reverses. The stabilisation ring is able to stabilise fan performance as it contains a set of static vanes. These static vanes redirect the reverse flow into an axial direction, and then reintroduce it into the mainstream flow upstream of the blades, Figure 10. This stabilises the fans characteristic, with the fans now exhibiting a pressure characteristic that rises continuously back to zero flow.

In 1965, Ivanov patented the first stabilisation ring [60]; however, the use of a full set of guide vanes upstream of the fan was difficult to apply in practical applications. Later Karlsson and Holmkvist [61] developed the stabilisation ring concept that incorporated the static vanes into a ring fitted around the fan casing. Despite the effectiveness of Karlsson and Holmkvist's stabilisation ring concept, it does have one unintended negative consequence. A fan fitted with a stabilisation ring will lose between 2 and 5 per cent efficiency as a direct consequence of the stabilisation ring [46].

The advent of the Energy using Product (EuP) Directive within the European Union has resulted in a mandatory minimum Fan and Motor Efficiency Grades (FMEGs) that became legally binding on 1 January, 2013. The minimum FMEGs will increase on 1 January, 2015. The industrial fan community widely expects that at some point in the future minimum allowable FMEGs will effectively render stabilisation rings obsolete as a consequence of their negative effect on fan 


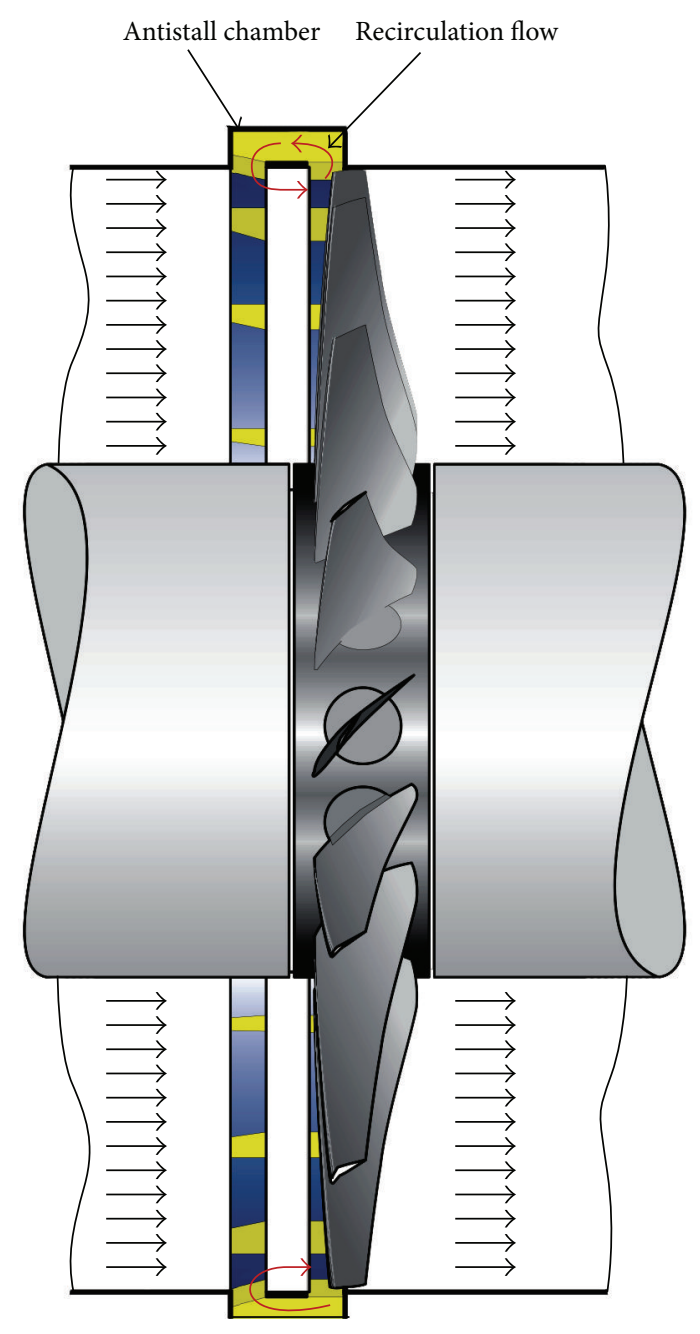

FIGURE 9: An axial flow fan fitted with an anti-stall ring. The antistall ring comprises an extension to the fan casing just over and upstream of the blades. The anti-stall casing incorporates static vanes, shown in yellow. As a fan approaches stall the flow though the fan is centrifuged up the blades and stalls as the flow spills out of the fan inlet. The blades redirect the flow in an axial direction, and reintroduce it upstream. This process of straightening and reintroducing the flow stabilises the fan's performance, eliminating the drop in pressure developing capability classically associated with a fan operating in a stalled condition [72].

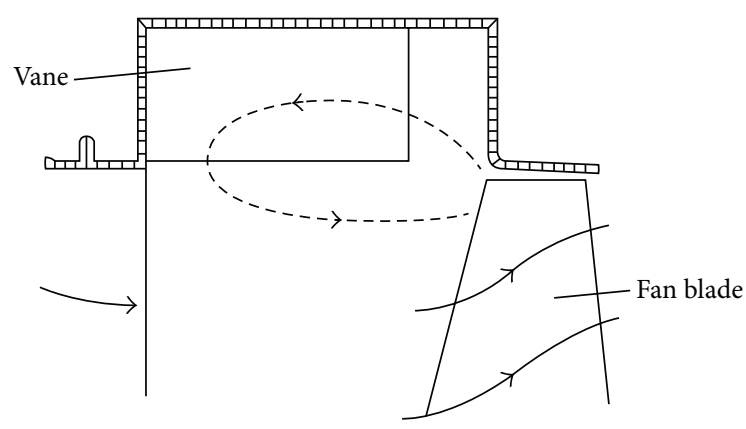

FIGURE 10: The proposed "stabilisation ring" arrangement adapted from Karlsson and Holmkvist [61] by Bard [73].

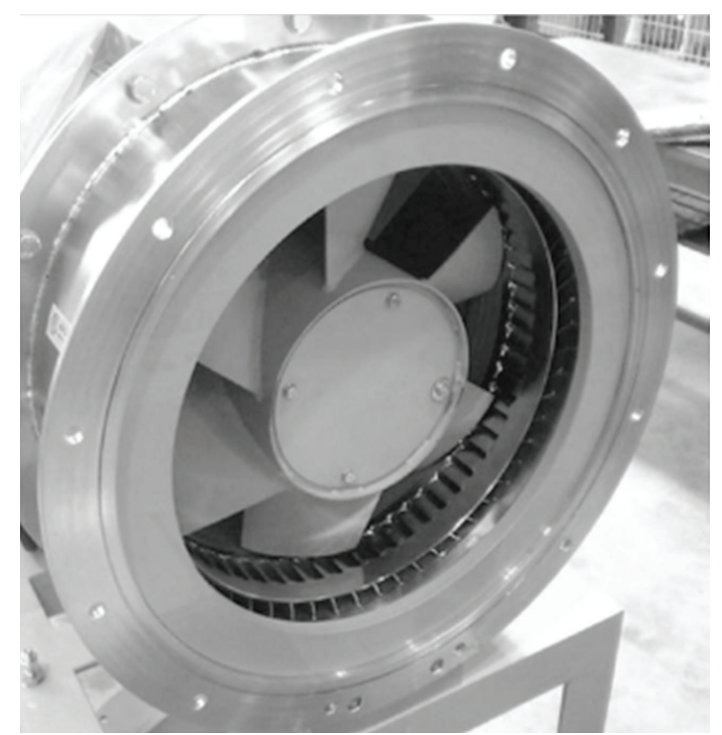

FIgURE 11: An axial fan mounted in a casing containing an air separator [63].

efficiency. At some point in the future the reduction in efficiency that engineers associate with stabilisation ring applications will result in the fan's FMEG falling below the allowed minimum.

Houghton and Day [62] present a possible way forward for industrial fan designers who are no longer able to utilise stabilisation rings, demonstrating that a compressor's stall resistance may be improved by incorporating a groove into the compressor's casing. The groove was located approximately 50 per cent of blade chord upstream of the blade's leading edge. Incorporating a groove into the compressor casing did not result in reducing compressor efficiency, and consequently, a possible avenue of endeavor for industrial fan designers who are no longer able to apply stabilisation rings because of their negative effect on fan efficiency is to study casing groove application into industrial fan casings.

4.8. Passive: Air Separators. Air separators are able to effectively suppress the onset of stall. Yamaguchi et al. [63] designed an air separator which has radial vanes with their leading-edges facing the fan rotor blade tips so as to "scoop" the tip flow, Figure 11. The air separator differs from a stabilisation ring in that air separator vanes are radial, in contrast to a stabilisation ring vanes that are axial. Yamaguchi et al. [63] studied the air separator and analysed its stall suppression effects on a low-speed single-stage, lightly loaded axial flow fan. In the air separator's recirculation passage downstream from the inlet cavity, a series of circumferential vanes correct the swirl flow in the axial direction. When the fan approaches stall there is an increase in swirl speed and centrifugal force on stall cells. This causes the stall cells to centrifuge spontaneously into the air separator's inlet. Air separators therefore separate stall cells from the main flow, and as a consequence of requiring no moving parts, constitute a passive stall control method. 
TABLE 2: Matrix of stall control techniques.

\begin{tabular}{|c|c|c|c|}
\hline Technique & Classification & How it works & Results \\
\hline Blade pitch control & Active & $\begin{array}{l}\text { Changes the fluid dynamics; changing the pitch } \\
\text { angle. }\end{array}$ & Acts after stall detection [36]. \\
\hline Rotational frequency control & Active & $\begin{array}{l}\text { Changes the fluid dynamics; controlling the } \\
\text { rotor speed. }\end{array}$ & Acts after stall detection [31]. \\
\hline Air injection & Active & $\begin{array}{l}\text { Rotating stall inception is achieved using } \\
\text { full-span distributed jet actuation. }\end{array}$ & $\begin{array}{l}\text { The nonideal injection reduces the } \\
\text { stall range's extension by about the } \\
\text { same proportion of the effective } \\
\text { pressure increase [56]. }\end{array}$ \\
\hline Bleed valve & Active & $\begin{array}{l}\text { Maintain the average flow through the } \\
\text { compressor above the critical flow. The air } \\
\text { bleeds from the plenum, so as to increase the } \\
\text { flow through the compressor. }\end{array}$ & $\begin{array}{l}\text { Recirculation alters the compressor } \\
\text { operating point. Only use the } \\
\text { recirculation or ambient bleeding } \\
\text { when stall is imminent }[57,58] \text {. }\end{array}$ \\
\hline Stabilisation rings & Passive & $\begin{array}{l}\text { Changes the fluid dynamics; provides the } \\
\text { stalled flow with a route back into the impeller. }\end{array}$ & Not sure that the stall occurs [72]. \\
\hline Air separator & Passive & $\begin{array}{l}\text { A series of circumferential vanes correct the } \\
\text { swirl flow in the axial direction; the stall cells } \\
\text { centrifuge spontaneously into the air separator } \\
\text { inlet and separate from the main flow. }\end{array}$ & $\begin{array}{l}\text { Air separators are able to effectively } \\
\text { suppress the stall zone after the stall } \\
\text { cells appear [63]. }\end{array}$ \\
\hline
\end{tabular}

The four active and two passive stall control techniques, Table 2, each represent a valid approach to the control of stall. Researchers have developed and utilised each in different industrial fan or compressor applications where the technique has proven effective. In practice it is stabilisation rings that are the most widespread application in industrial fans and bleed valves that are the most widespread application in compressors. The other active and passive stall control techniques are the subject of research in an on-going effort to better understand the flow physics that underpin stall and development in order to improve industrial fan and compressor stability.

\section{Stall Detection Systems}

Stall control techniques have proven effective in service; however, they are inevitably reactive. Stall control techniques require the fan to be stalling before they have any effect. In many applications it would be more appropriate for the control system to take action to avoid stall before it occurs, as opposed to managing the consequences of stall having occurred. For a control system to take action to avoid stall it is necessary to first predict stall onset. Predicting stall onset is challenging, and is an ongoing research subject in both the industrial fan and compressor community. Despite the challenges of predicting stall onset, it remains an essential precursor to the development of a more effective stall control system.

Stall detection systems that identify stall onset have the potential to form an input into a proactive stall control system theoretically capable of reacting before a fan actually stalls. Researchers recognise that studying stall detection both in industrial fans and compressors as critical to developing a stall management system. To form an effective input into a stall management system, a stall detection system requires as input the output from high frequency response sensors located in the industrial fan or compressor blades' immediate vicinity. Researchers then use the output from high frequency response sensors to identify stall precursors, and when detected, to generate a warning signal that inputs into the stall control system. The stall control system is then able to take remedial action to prevent the identified stall precursors from developing further.

Wadia et al. [64] and Christensen et al. [65] have proposed stall management systems based on instantaneous near-field pressure measurements. They have studied the effectiveness of stall detection systems as part of a stall management system when applied to a multistage high-speed compressor test rig. A challenge that both research teams faced was the very short time between the identification of stall precursors and compressor stall. Although stall detection systems have the potential to provide a useful input into compressor stall management systems, those stall management systems must be capable of reacting within a few milliseconds if they are to use an input from a stall detection system effectively.

5.1. Two-Point Spatial Correlation. In axial fans instabilities occur primarily as wave-like disturbances around the annulus in the circumferential direction. In the initial state of instability the disturbance amplitude is small, but increases with the evolution of the instability. One may use spatially adjacent fast-response pressure transducers, microphones or hot wire anemometers to identify stall precursors. Researchers associate these precursors with the formation of threedimensional disturbances of finite amplitude, located in the blade tip region. These are characterised by a spike in the signal which fast response transducers record.

In order to accurately identify the spike in a signal recorded by a fast response transducer as a stall precursor, it is important to characterise the stall inception process dynamics. Only in characterising the stall inception process can one distinguish between spikes that occur with stall inception from background noise. Spike isolation is possible using a windowed two-point spatial correlation which provides spatial and temporal information about rotating features in 
the flow [66]. The windowed two-point spatial correlation technique is insensitive to low pass filtering and parameter selection over a wide range of values and is valuable for analysing both pre-stall and stall inception behaviour [66].

5.2. Stochastic Model. The stochastic model for detecting stall precursors utilises an autocorrelation technique. The signals from two circumferentially off-set high frequency response pressure probes mounted in the industrial fan or compressor casing close to the blade tips are autocorrelated. The correlation typically decreases as the compressor or fan approaches its stability limit, and therefore tracking the correlation provides a measure of the industrial fan or compressor's proximity to its stability limit. Dhingra et al. [67] developed the stochastic model. They developed an autocorrelating algorithm and established a minimum threshold correlation value that corresponded to the imminent onset of compressor stall. Although able to demonstrate that the stochastic model could form the basis of a stall detection system, the researchers conducted their reported work in a laboratory and did not include the development of a stall management system that utilised the stochastic model output as an input.

5.3. Travelling Wave Energy Analysis. An alternative modelling approach to either the two-point special correlation or stochastic model is travelling wave analysis. Travelling wave analysis involves calculating wave energy, which we define as the difference between positive and negative frequency power spectra. We then compute an "energy index" for a fixed-time window that must extend to include the spatial Fourier modes within it. Tryfonidis et al. [68] developed the travelling wave analysis as a real time measure of compressor stability. By providing a real timer measure of compressor stability, the analysis technique is useful for providing early warning of spike-type stall inception in high-speed compressors.

5.4. Cross-Correlation Analysis. Cross-correlation analysis is a further analytical approach that cross-correlates a pair of near-field pressure signals. Developed by Park [69], the analytical approach is based on the observation that short wavelength disturbances that are recognisably spike-like indications of incipient stall form and decay many rotor revolutions before stall occurs. By cross-correlating the signal from a single high frequency response pressure sensor, we can correlate the presence of spike-like pulses in the pressure signal from one rotor revolution to the next. The analysis produces a similar output to that of the two-point spatial correlation technique but requires only one sensor and is therefore more practical in real world stall detection system embodiments.

5.5. Acoustic Stall Detection. The symmetrised dot pattern (SDP) stall detection technique is based on an industrial fan or compressor acoustic pressure signal's visual waveform analysis [41]. The symmetrised dot pattern technique differentiates between critical and noncritical stall conditions and provides a form of visualisation that enables one to identify stall precursors. Bianchi et al. [36] first reconstructed the symmetrised dot patterns from the unsteady pressure which they measured on an industrial fan's casing and more recently

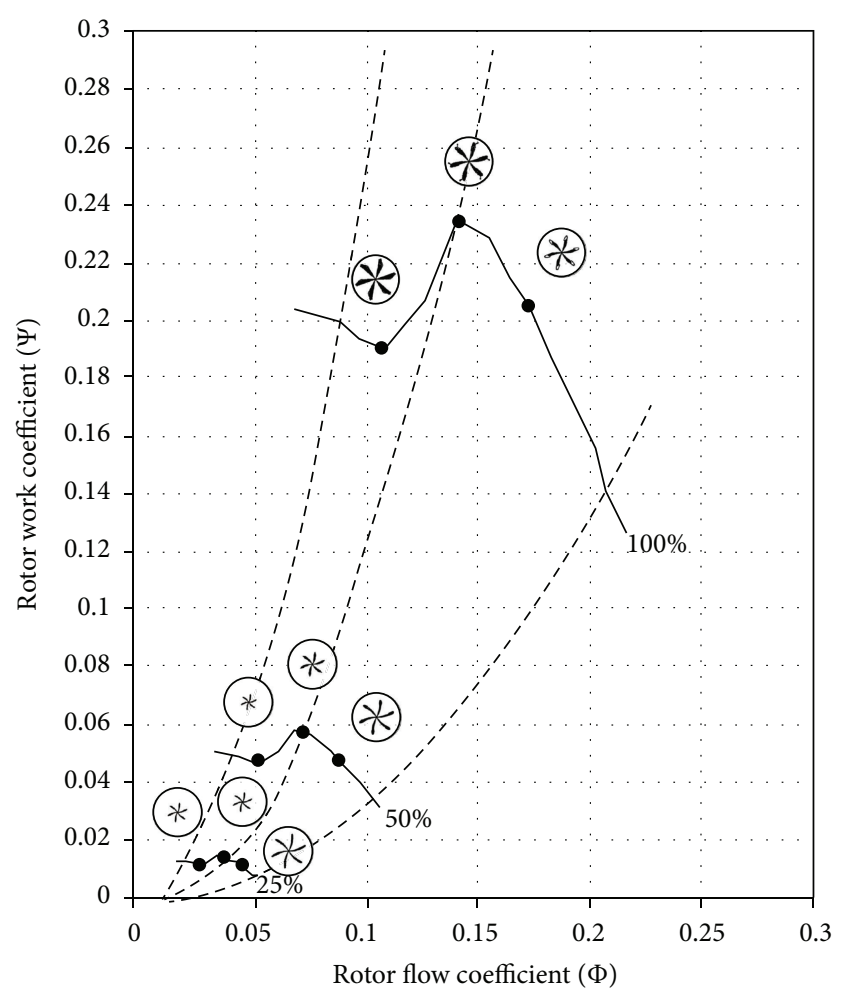

FIgURE 12: Unsteady pressure data from a 2.24 meter diameter tunnel ventilation fan at 100 per cent, 50 per cent, and 25 per cent speed in stable operation, when stall is incipient and during stalled operation. The authors processed the data using the symmetrised dot pattern (SDP) technique to produce a set of patterns that are distinctly different at each speed and operating condition [41].

[70] demonstrated the proposed technique's validity using a symmetrised dot pattern technique from sound pressure signals. This enabled them to extend the technique to the use of measured acoustic pressure signals in different locations in an industrial fan's acoustic far field.

The symmetrised dot pattern technique generates images that one may use as the basis of a stall detection methodology [41]. One may process unsteady pressure or acoustic signals using the symmetrised dot pattern technique to generate distinctly different images at different fan speeds and operating conditions, Figure 12. The images which the technique produces are distinctly different during stable operation, when stall is incipient and during stalled operation.

An ability to generate images sufficiently different to enable engineers to differentiate between stable operation, incipient stall and stalled operation results in a symmetrised dot pattern technique with the potential to form the basis of a stall detection system. Applying Bianchi et al.s [71] symmetrised dot pattern technique to acoustic measurements constitutes a significant advance over the two-point spatial correlation, the stochastic model, travelling wave energy analysis or cross-correlation analysis as one can generate the images using a single acoustic signal. The other techniques require mounting a high frequency response pressure transducer in the industrial fan or compressor casing over the blades that 


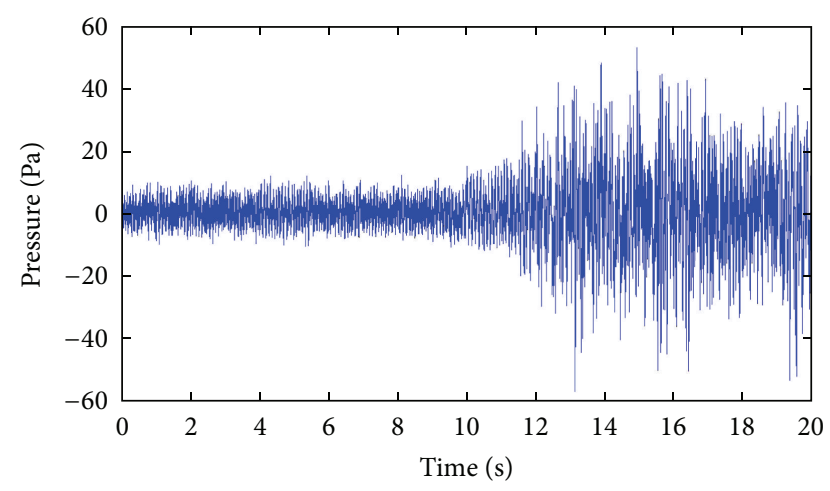

FIGURE 13: Data logged at $2000 \mathrm{~Hz}$ from a high frequency response pressure transducer located in the inlet box of an induced draft fan. From zero to ten seconds, the fan is operating in a stable condition. At ten seconds, stall becomes incipient. From ten to 20 seconds stall remains incipient.

are prone to stall. In contrast, one may apply the symmetrised dot pattern technique to acoustic measurement made with a single microphone at any location in close proximity to the industrial fan or compressor. The technique is particularly effective compared to other techniques when the signal of interest is low compared to the background noise [71]. This enables the symmetrised dot pattern technique to provide useful results when the microphone is situated in the acoustic far-field.

We can differentiate the symmetrised dot pattern technique from other stall detection systems as it can identify a shift from stable operation to incipient stall an order of magnitude more quickly than other techniques. Other stall detection techniques use a Fourier analysis to analyse raw pressure signals which generate the signal's frequency spectrum. They then identify a change in frequency spectrum as a fan moves from stable operation to incipient stall. A weakness associated with using a Fourier analysis is that the minimum sample size needed is relatively large compared to that required by the symmetrised dot pattern technique. Consequently, the other techniques require a longer data acquisition period that is required by the symmetrised dot pattern technique. The shorter the required data acquisition period needed for the signal analysis to be effective, the more likely that the resultant output will be available quickly enough to provide a warning that stall is incipient before a fan transitions into stalled operation.

We may illustrate the effectiveness of the symmetrised dot pattern technique when compared with any of the Fourier transform based stall detection techniques with an example. We present the output from a high frequency pressure transducer located in the far-field for a 20 -second period during which the fan operating point moves from stable operation to incipient stall, Figure 13. In this context far-field refers to a pressure transducer located in the inlet box of an induced draft fan. The reason for using data from the far-field is that it extends stall detection from the hydrodynamic pressure near-field to the acoustic pressure far-field. In this example, we logged data at $2000 \mathrm{~Hz}$. From zero to ten seconds the
Frequency spectrum for 10 rotor revolutions during stable operation

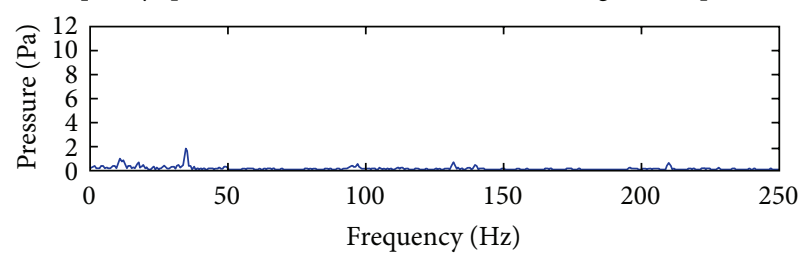

(a)

Frequency spectrum for 10 rotor revolutions during incipient stall

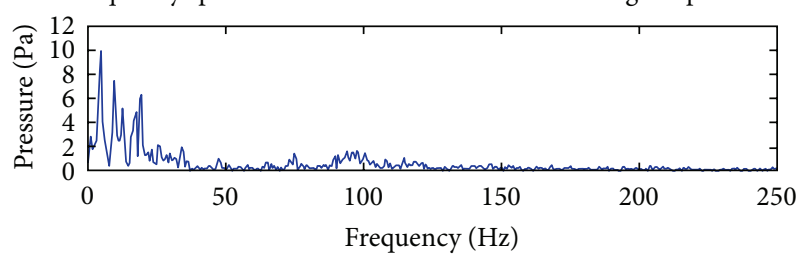

(b)

FIGURE 14: Frequency spectrum generated using data from over ten rotor revolutions during stable fan operation (top) and over ten rotor revolutions when stall is incipient (bottom).. The frequency spectrum generated using data when stall is incipient (b) includes features that are associated with the spike-like pressure pulses that occur when stall is incipient. As such, the two frequency spectrums are different enabling one to use them as the basis of a stall detection system.

fan is operating in its operating characteristic's stable region. At ten seconds stall becomes incipient, and remains incipient for one second. From 11 to 20 seconds the fan is operating in its operating characteristic's unstable region.

A Fourier analysis of ten rotor revolutions of data $(0.1$ seconds) during stable operation, immediately before ten seconds, Figure 13, and ten rotor revolutions of data when stall is incipient, immediately after ten seconds, Figure 13, results in distinctly different frequency spectrum, Figure 14. This difference between the two frequency spectra below $50 \mathrm{~Hz}$ is a consequence of the spike-like pressure pulses associated with incipient stall present in the data from ten to 20 seconds, and absent in the data from zero to ten seconds. We used the difference between the frequency spectrum that we generated using the data from a stable operating condition and an operating condition where stall is incipient as the basis of Fourier transform based stall warning techniques.

The signal processing associated with the symmetrised dot pattern technique does not involve a Fourier transform, instead of transforming the data into a set of polar coordinates that one uses to create the symmetrised dot patterns. In the above example, stall becomes incipient at ten seconds, Figure 13. One rotor revolution of data ( 0.01 seconds) during stable operation, immediately before ten seconds, Figure 13, and one rotor revolution of data when stall is incipient, immediately after ten seconds, Figure 13, results in distinctly different symmetrised dot patterns, Figure 15. It is the difference between the generated symmetrised dot pattern using the data from a stable operating condition and an operating condition where stall is incipient that enable one to use the symmetrised dot pattern technique as the basis of a stall warning technique. 


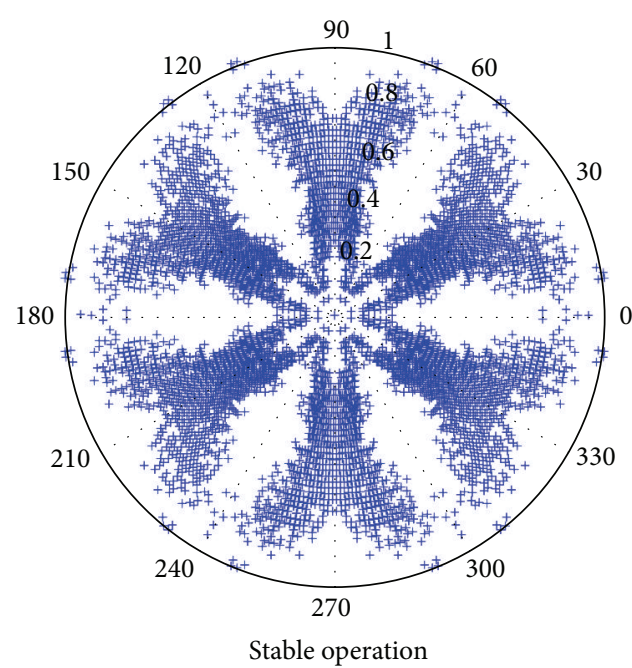

(a)

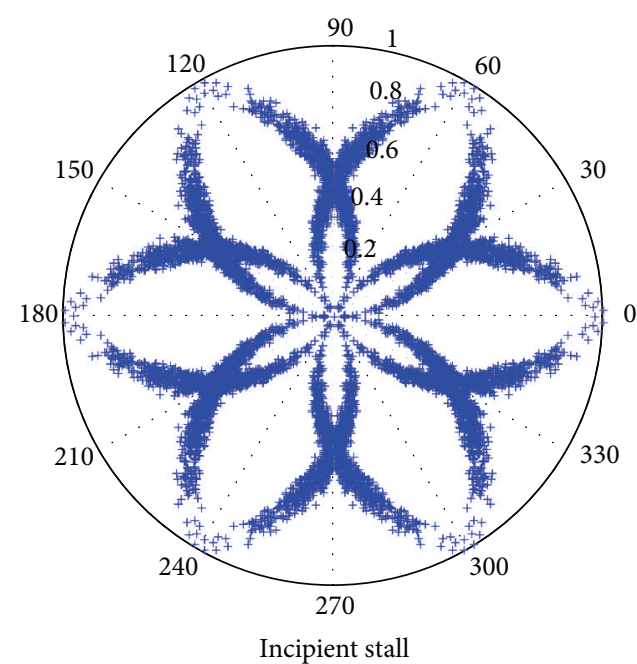

(b)

FIGURE 15: Symmetrised dot patterns generated using data from over one rotor revolution during the fan's stable operation (a) and over one rotor revolution when stall is incipient (b). The two patterns are different enabling one to use them as the basis of a stall detection system.

TABle 3: Matrix of stall detection techniques.

\begin{tabular}{|c|c|c|}
\hline Technique of detection & How it works & Results \\
\hline Two-point spatial correlation & $\begin{array}{l}\text { Finds spikes inception in the signal before the } \\
\text { stall happens. }\end{array}$ & $\begin{array}{l}\text { Valuable for analysis of prestall and } \\
\text { stall inception [66]. }\end{array}$ \\
\hline Stochastic model & $\begin{array}{c}\text { Correlates the pressure transducers' signals on } \\
\text { the casing over the rotor tips. Finds dips in the } \\
\text { correlation. }\end{array}$ & Used for stall detection [67]. \\
\hline Travelling-wave-energy analysis & $\begin{array}{l}\text { Uses fan dynamics to introduce the concept of } \\
\text { travelling wave energy as a real time measure of } \\
\text { compressor stability. }\end{array}$ & $\begin{array}{l}\text { Early warning for spikes; good for high } \\
\text { speed compressors [68]. }\end{array}$ \\
\hline Cross-correlation analysis & $\begin{array}{l}\text { Searches for short wavelength disturbances } \\
\text { recognisable as spikes that form and decay } \\
\text { before the stall. }\end{array}$ & $\begin{array}{l}\text { Finds the spike inception, but does not } \\
\text { use the instantaneous signal [69]. }\end{array}$ \\
\hline Acoustic stall detection & $\begin{array}{l}\text { Expresses the time-series signal's changes in } \\
\text { amplitude and frequency. }\end{array}$ & $\begin{array}{l}\text { Discerns from critical and noncritical } \\
\text { stall using an easy to understand visual } \\
\text { waveform analysis [41]. }\end{array}$ \\
\hline
\end{tabular}

When one conducts a Fourier analysis using the same one rotor revolution of data to generate each symmetrised dot pattern, the resultant frequency spectrum for the stable operating condition and an operating condition where stall is incipient are similar, Figure 16. A consequence of the frequency spectrum being similar is that any of the stall warning techniques based upon the use of a Fourier analysis will not be able to use the frequency spectrum to differentiate between a fan in stable operation and when stall is incipient. By contrast, the symmetrised dot pattern technique is able to generate distinctly different patterns, indicating that the symmetrised dot pattern technique can identify a change from a stable operating condition to one where stall is incipient an order of magnitude more rapid than stall warning techniques based on the use of a Fourier transform based analysis.

The five stall detection techniques, Table 3 , each represent a valid approach to stall detection. In practice it is the twopoint spatial correlation technique that is the most developed stall detection technique in compressor applications and the symmetrised dot pattern technique that is the most widespread application in industrial fan applications. Stall detection systems well enough developed for in-service applications are still the subject of development in both the industrial fan and compressor communities. Research is ongoing in an effort to better understand the flow physics that occur with incipient stall in order to improve the accuracy and speed with which one can identify incipient stall.

\section{Conclusions}

This paper aimed to provide an overview of stall control technologies for industrial fans. These control technologies play an important role in many industrial applications. We have examined the stall phenomenon and paid particular attention to fluid dynamics, stall inception, and mechanical failure that may occur when operating industrial fans. We then 
Frequency spectrum for 1 revolution during stable operation

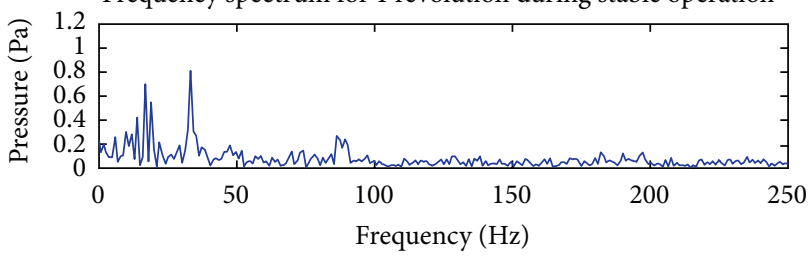

(a)

Frequency spectrum for 1 rotor revolution during incipient stall

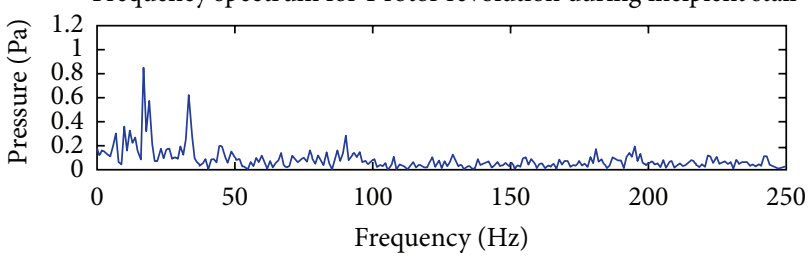

(b)

FIGURE 16: Frequency spectrum generated using data from over one rotor revolution during the fan's stable operation (top) and over one rotor revolution when stall is incipient (bottom). The two frequency spectrums are similar and therefore can't be used as the basis of a stall detection system.

introduced the technologies that exist today for stall identification and control, distinguishing between active and passive technologies. We can use passive technologies to prevent the worst stall consequence: mechanical failures. Industrial fan manufacturers primarily use passive control technologies in service.

Although innovation in passive technology is possible, passive technologies generally reduce fan efficiency. Current regulation within the European Union and planned regulation in the USA sets minimum Fan and Motor Efficiency Grades (FMEGs) for industrial fans. These minimum FMEGs will rise in the European Union on 1 January, 2015, and will continue to rise both within Europe and the USA in an ongoing effort to reduce carbon emissions. As such, it is likely that the efficiency penalty with using passive technologies in industrial fan applications will become progressively less acceptable over the coming decade.

Researchers are focusing on active stall control technologies in an on-going effort to develop effective stall detection system. Active stall control technologies include technologies that are still the subject of both fundamental research and applied development and therefore, at the time of writing, are still immature. Despite the need for further research and development of active stall control systems, and their associated stall detection systems, they offer the greatest potential for medium term improvement. We can most readily realise the potential for medium term improvement in industrial fan applications, as industrial fans are relatively low speed machines in comparison to compressors. Consequently, active stall control systems based upon stall detection have the potential for practical application in industrial fans first, with the experience gaining in industrial fan application informing the development of higher speed systems that engineers can then use in compressor applications.

\section{References}

[1] B. de Jager, "Rotating stall and surge control: a survey," in Proceedings of the 34th IEEE Conference on Decision and Control, pp. 1857-1862, New Orleans, LA, USA, December 1995.

[2] E. M. Greitzer, "Review-axial compressor stall phenomena," Journal of Fluids Engineering, Transactions of the ASME, vol.102, no. 2, pp. 134-151, 1980.

[3] I. J. Day and N. A. Cumpsty, "The measurement and interpretation of flow within rotating stall cells in axial compressors," Journal of Mechanical Engineering Science, vol. 20, no. 2, pp. 101114, 1978.

[4] F. K. Moore, "A theory of rotating stall of multistage compressors, parts I-III," Journal of Engineering for Gas Turbines and Power, vol. 106, no. 2, pp. 313-336, 1984.

[5] H. W. Emmons, C. E. Pearson, and H. P. Grant, "Compressor surge and stall propagation," Transactions of the ASME, vol. 77, pp. 455-469, 1955.

[6] J. T. Gravdahl and O. Egeland, Compressor Surge and Rotating Stall: Modeling and Control, Springer, London, UK, 1999.

[7] A. G. Sheard and A. Corsini, "The mechanical impact of aerodynamic stall on tunnel ventilation fans," International Journal of Rotating Machinery, vol. 2012, Article ID 402763, 12 pages, 2012.

[8] D. A. Fink, N. A. Cumpsty, and E. M. Greitzer, "Surge dynamics in a free-spool centrifugal compressor system," Journal of Turbomachinery, vol. 114, no. 2, pp. 321-332, 1992.

[9] A. M. Wo and J. P. Bons, "Flow physics leading to system instability in a centrifugal pump," Journal of Turbomachinery, vol. 116, no. 4, pp. 612-621, 1994.

[10] J. D. Paduano, A. H. Epstein, L. Valavani, J. P. Longley, E. M. Greitzer, and G. R. Guenette, "Active control of rotating stall in a low-speed axial compressor," Journal of Turbomachinery, vol. 115, no. 1, pp. 48-57, 1993.

[11] J. Parduano, L. Valavani, and A. H. Epstein, "Parameter identification of compressor dynamics during closed-loop operation," Journal of Dynamic Systems, Measurement and Control, vol. 115, no. 4, pp. 694-703, 1993.

[12] J. D. Paduano, L. Valavani, A. H. Epstein, E. M. Greitzer, and G. R. Guenette, "Modeling for control of rotating stall," Automatica, vol. 30, no. 9, pp. 1357-1373, 1994.

[13] J. E. Pinsley, G. R. Guenette, A. H. Epstein, and E. M. Greitzer, "Active stabilization of centrifugal compressor surge," Journal of Turbomachinery, vol. 113, no. 4, pp. 723-732, 1991.

[14] C. Rodgers, "Centrifugal compressor inlet guide vanes for increased surge margin," Journal of Turbomachinery, vol. 113, no. 4, pp. 696-702, 1991.

[15] J. S. Simon and L. Valavani, "A Lyapunov based nonlinear control scheme for stabilizing a basic compression system using a close-coupled control valve," in Proceedings of the American Control Conference, vol. 3, pp. 2398-2406, June 1991.

[16] J. S. Simon, L. Valavani, A. H. Epstein, and E. M. Greitzer, "Evaluation of approaches to active compressor surge stabilization," Journal of Turbomachinery, vol. 115, no. 1, pp. 57-67, 1993.

[17] I. J. Day, "Axial compressor performance during surge," Journal of Propulsion and Power, vol. 10, no. 3, pp. 329-336, 1994.

[18] G. Eisenlohr and H. Chladek, "Thermal tip clearance control for centrifugal compressor of an APU engine," Journal of Turbomachinery, vol. 116, no. 4, pp. 629-634, 1994.

[19] A. H. Epstein, J. E. F. Williams, and E. M. Greitzer, "Active suppression of aerodynamic instabilities in turbomachines," Journal of Propulsion and Power, vol. 5, no. 2, pp. 204-211, 1989. 
[20] K. M. Eveker and C. N. Nett, "Model development for active surge control/rotating stall avoidance in aircraft gas turbine engines," in Proceedings of the American Control Conference, pp. 3166-3172, June 1991.

[21] K. M. Eveker and C. N. Nett, "Control of compression system surge and rotating shell: a laboratory-based 'hands-on' introduction," in Proceedings of the American Control Conference, vol. 2, pp. 1307-1311, June 1993.

[22] K. M. Eveker, D. L. Gysling, C. N. Nett, and O. P. Sharma, "Integrated control of rotating stall and surge in aeroengines," in Sensing, Actuation, and Control in Aeropropulsion, pp. 21-35, April 1995.

[23] J. E. F. Williams, M. F. L. Harper, and D. J. Allwright, "Active stabilization of compressor instability and surge in a working engine," Journal of Turbomachinery, vol. 115, no. 1, pp. 68-75, 1993.

[24] J. E. F. Williams and X. Y. Huang, "Active stabilization of compressor surge," Journal of Fluid Mechanics, vol. 204, pp. 245262, 1989.

[25] A. Goto, "Suppression of mixed-flow pump instability and surge by the active alteration of impeller secondary flows," Journal of Turbomachinery, vol. 116, no. 4, pp. 621-628, 1994.

[26] E. M. Greitzer and F. K. Moore, "A theory of post-stall transients in axial compression systems: part II-application," Journal of Engineering for Gas Turbines and Power, vol. 108, no. 2, pp. 231239, 1986.

[27] D. L. Gysling, M. Dugundji, J. E. Greitzer, and A. H. Epstein, "Dynamic control of centrifugal compressor surge using tailored structures," Journal of Turbomachinery, vol. 113, no. 4, pp. 710-722, 1991.

[28] W. W. Copenhaver and T. H. Okiishi, "Rotating stall performance and recoverability of a high-speed 10-stage axial flow compressor," Journal of Propulsion and Power, vol. 9, no. 2, pp. 281-292, 1993.

[29] I. J. Day, "Stall inception in axial flow compressors," Journal of Turbomachinery, vol. 115, no. 1, pp. 1-9, 1993.

[30] K. H. Kim and S. Fleeter, "Compressor unsteady aerodynamic response to rotating stall and surge excitations," Journal of Propulsion and Power, vol. 10, no. 5, pp. 698-708, 1994.

[31] S. Bianchi, A. Corsini, and A. G. Sheard, "Detection of stall regions in a low-speed axial fan, part 1: azimuthal acoustic measurements," in Proceedings of the 55th American Society of Mechanical Engineers Turbine and Aeroengine Congress, Glasgow, UK, Paper No. GT2010-22753, June 2010.

[32] M. M. Bright, H. Qammar, H. Vhora, and M. Schaffer, "Rotating pip detection and stall warning in high-speed compressors using structure function," in Proceedings of the AGARD RTO AVT Conference, Toulouse, France, May 1998.

[33] T. R. Camp and I. J. Day, "A study of spike and modal stall phenomena in a low-speed axial compressor," Journal of Turbomachinery, vol. 120, no. 3, pp. 393-401, 1998.

[34] A. Deppe, H. Saathoff, and U. Stark, "Spike-type stall inception in axial flow compressors," in Proceedings of the 6th Conference on Turbomachinery, Fluid Dynamics and Thermodynamics, pp. 178-188, Lille, France, 2005.

[35] H. D. Vo, C. S. Tan, and E. M. Greitzer, "Criteria for spike initiated rotating stall," in Proceedings of the 50th American Society of Mechanical Engineers Gas Turbine and Aeroengine Congress, Reno, NV, USA, Paper No. GT2005-68374, June 2005.

[36] S. Bianchi, A. Corsini, L. Mazzucco, L. Monteleone, and A. G. Sheard, "Stall inception, evolution and control in a low speed axial fan with variable pitch in motion," Journal of Engineering for Gas Turbines and Power, vol. 134, no. 4, Article ID 042602, 10 pages, 2012.

[37] N. A. Cumpsty, "Part-circumference casing treatment and the effect on compressor stall," in Proceedings of the 34th American Society of Mechanical Engineers Gas Turbine and Aeroengine Congress, Toronto, ON, Canada, Paper No. 89-GT-312, June 1989.

[38] L. Mongeau, D. E. Thompson, and D. K. Mclaughlin, "A method for characterizing aerodynamic sound sources in turbomachines," Journal of Sound and Vibration, vol. 181, no. 3, pp. 369389, 1995.

[39] K. Okada, "Experiences with flow-induced vibration and low frequency noise due to rotating stall of centrifugal fan," Journal of Low Frequency Noise and Vibration, vol. 6, no. 2, pp. 76-87, 1987.

[40] F. Kameier and W. Neise, "Rotating blade flow instability as a source of noise in axial turbomachines," Journal of Sound and Vibration, vol. 203, no. 5, pp. 833-853, 1997.

[41] A. G. Sheard, A. Corsini, and S. Bianchi, "Detection of stall regions in a low-speed axial fan, part 2: stall warning by visualisation of sound signals," in Proceedings of the 55th American Society of Mechanical Engineers Turbine and Aeroengine Congress, pp. 14-18, Glasgow, UK, Paper No. GT2010-22754, June 2010.

[42] A. Rippl, Experimentelle Untersuchungen Zuminstationaren Betriebsverhahenan der Stabilitarsgrenze Eines Mehrstufigen Transsonischen Verdichters [Ph.D. thesis], Ruhr-Universitat Bochum, 1995.

[43] A. G. Sheard and N. M. Jones, "Powered smoke and heat exhaust ventilators: the impact of EN 12101-3 and ISO 21927-3," Tunnelling and Underground Space Technology, vol. 28, no. 1, pp. 174-182, 2012.

[44] EN12101-3, "Smoke and heat control systems. Specification for powered smoke and heat exhaust ventilators," 2002.

[45] ISO and 21927-3, "Smoke and heat control systems-part 3: specification for powered smoke and heat exhaust ventilators.", 2006.

[46] A. G. Sheard and A. Corsini, "The impact of an anti-stall stabilisation ring on industrial fan performance: implications for fan selection," in Proceedings of the 56th American Society of Mechanical Engineers Turbine and Aeroengine Congress, Vancouver, BC, Canada, Paper No. GT2011-45187, June 2011.

[47] D. Borello, A. Corsini, G. Delibra, F. Rispoli, and A. G. Sheard, "Numerical investigation on the aerodynamics of a tunnel ventilation fan during pressure pulses," in Proceedings of the 10th European Turbomachinery Conference, pp. 573-582, Lappeenranta, Finland, April, 2013.

[48] M. Gad-el-Hak, Flow Control: Passive, Active, and Reactive Flow Management, Cambridge University Press, Cambridge, UK, 2000.

[49] R. D. Joslin, R. H. Thomas, and M. M. Choudhari, "Synergism of flow and noise control technologies," Progress in Aerospace Sciences, vol. 41, no. 5, pp. 363-417, 2005.

[50] K. L. Suder, M. D. Hathaway, S. A. Thorp, A. J. Strazisar, and M. B. Bright, "Compressor stability enhancement using discrete tip injection," Journal of Turbomachinery, vol. 123, no. 1, pp. 14-23, 2001.

[51] C. Nie, G. Xu, X. Cheng, and J. Chen, "Micro air injection and its unsteady response in a low-speed axial compressor," Journal of Turbomachinery, vol. 124, no. 4, pp. 572-579, 2002. 
[52] F. Lin, Z. Tong, S. Geng, J. Zhang, J. Chen, and C. Nie, "A summary of stall warning and suppression research with micro tip injection," in Proceedings of the 56th American Society of Mechanical Engineers Turbine and Aeroengine Congress, Vancouver, BC, Canada, Paper No. GT2011-46118, June 2011.

[53] H. J. Weigl, J. D. Paduano, L. G. Frechette et al., "Active stabilization of rotating stall and surge in a transonic single stage axial compressor," in Proceedings of the International Gas Turbine \& Aeroengine Congress \& Exposition, June 1997.

[54] H. D. Vo, J. Cameron, and S. Morris, "Control of short lengthscale rotating stall inception on a high-speed axial compressor with plasma actuation," in Proceedings of the 53rd American Society of Mechanical Engineers Gas Turbine and Aeroengine Congress, Berlin, Germany, Paper No. GT2008-50967, June 2008.

[55] T. C. Corke and M. L. Post, "Overview of plasma flow control: concepts, optimization, and applications," in Proceedings of the 43rd AIAA Aerospace Sciences Meeting and Exhibit, Reno, NV, USA, Paper No. AIAA 2005-563, January 2005.

[56] H. D. Vo, "Active suppression of rotating stall inception with distributed jet actuation," International Journal of Rotating Machinery, vol. 2007, Article ID 56808, 15 pages, 2007.

[57] J. V. R. Prasad, Y. Neumeier, M. Lal, S. H. Bae, and A. Meehan, "Experimental investigation of active and passive control of rotating stall in axial compressors," in Proceedings of the IEEE International Conference on Control Applications (CCA) and IEEE International Symposium on Computer Aided Control System Design (CACSD '99), pp. 985-990, August 1999.

[58] S. Yeung and R. M. Murray, "Reduction of bleed valve rate requirements for control of rotating stall using continuous air injection," in Proceedings of the IEEE International Conference on Control Applications, pp. 683-690, October 1997.

[59] C. S. Tan, I. Day, S. Morris, and A. Wadia, "Spike-type compressor stall inception, detection, and control," Annual Review of Fluid Mechanics, vol. 42, pp. 275-300, 2010.

[60] S. K. Ivanov, “Axial blower," US Patent, 3, 189-260, 1965.

[61] S. Karlsson and T. Holmkvist, "Guide vane ring for a return flow passage in axial fans and a method of protecting it," US Patent 4, 602, 410, 1986.

[62] T. Houghton and I. Day, "Enhancing the stability of subsonic compressors using casing grooves," Journal of Turbomachinery, vol. 133, no. 2, Article ID 021007, 11 pages, 2011.

[63] N. Yamaguchi, M. Ogata, and Y. Kato, "Improvement of stalling characteristics of an axial-flow fan by radial-vaned airseparators nobuyuki yamaguchi," Journal of Turbomachinery, vol. 132, no. 2, Article ID 021015, 10 pages, 2010.

[64] A. R. Wadia, D. Christensen, and J. V. Prasad, "Compressor stability management in aircraft engines," in Proceedings of the 25th Congress of the International Council of the Aeronautical Sciences, ICAS, Hamburg, Germany, 2006-5.4.2, Paper No. 759, 2006.

[65] D. Christensen, P. Cantin, D. Gutz et al., "Development and demonstration of a stability management system for gas turbine engines," Journal of Turbomachinery, vol. 130, no. 3, Article ID 031011, 9 pages, 2008.

[66] J. Cameron and S. Morris, "Spatial correlation based stall inception analysis," in Proceedings of the 52nd American Society of Mechanical Engineers Gas Turbine and Aeroengine Congress, pp. 14-17, Montreal, Canada, Paper No. GT2007-28268, May 2007.
[67] M. Dhingra, Y. Neumeier, J. V. R. Prasad, A. Breeze-Stringfellow, H.-W. Shin, and P. N. Szucs, "A stochastic model for a compressor stability measure," Journal of Engineering for Gas Turbines and Power, vol. 129, no. 3, pp. 730-737, 2007.

[68] M. Tryfonidis, O. Etchevers, J. D. Paduano, A. H. Epstein, and G. J. Hendricks, "Prestall behavior of several high-speed compressors," Journal of Turbomachinery, vol. 117, no. 1, pp. 6280, 1995.

[69] H. G. Park, Unsteady disturbance structures in axial flow compressor stall inception [M.S. thesis], Massachusetts Institute of Technology, Cambridge, MA, USA, 1994.

[70] S. Bianchi, A. Corsini, and A. G. Sheard, "Demonstration of a stall detection system for induced-draft fans," Journal of Power \& Energy, 2013.

[71] S. Bianchi, A. Corsini, and A. G. Sheard, "Experiments on the use of symmetrized dot patterns for in-service stall detection in industrial fans," Advances in Acoustic and Vibration, vol. 2013, Article ID 610407, 10 pages, 2013.

[72] Eurovent1/11, Fans and System Stall: Problems and Solution, 2007.

[73] H. Bard, "The stabilization of axial fan performance," in Proceedings of the Institution of Mechanical Engineers (IMechE) Conference C120/84 on the Installation Effects in Ducted Fan Systems, pp. 100-106, 1984. 

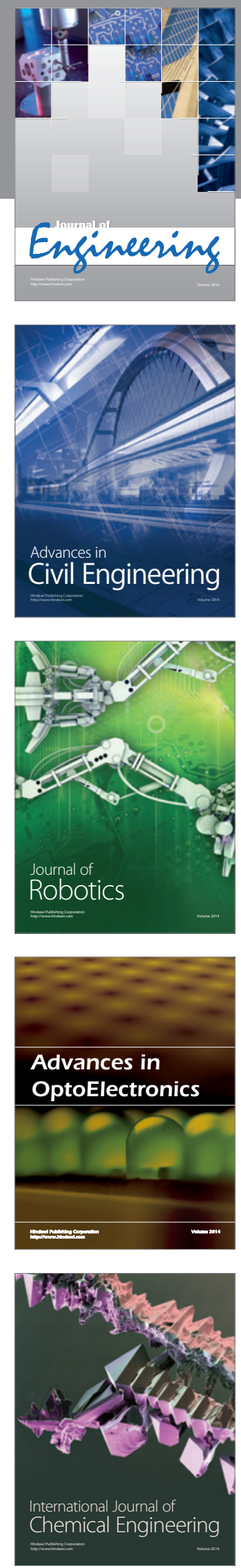

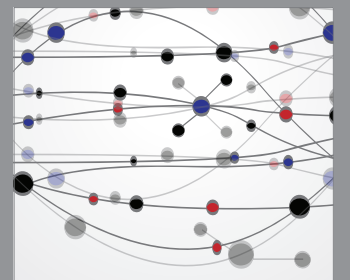

The Scientific World Journal
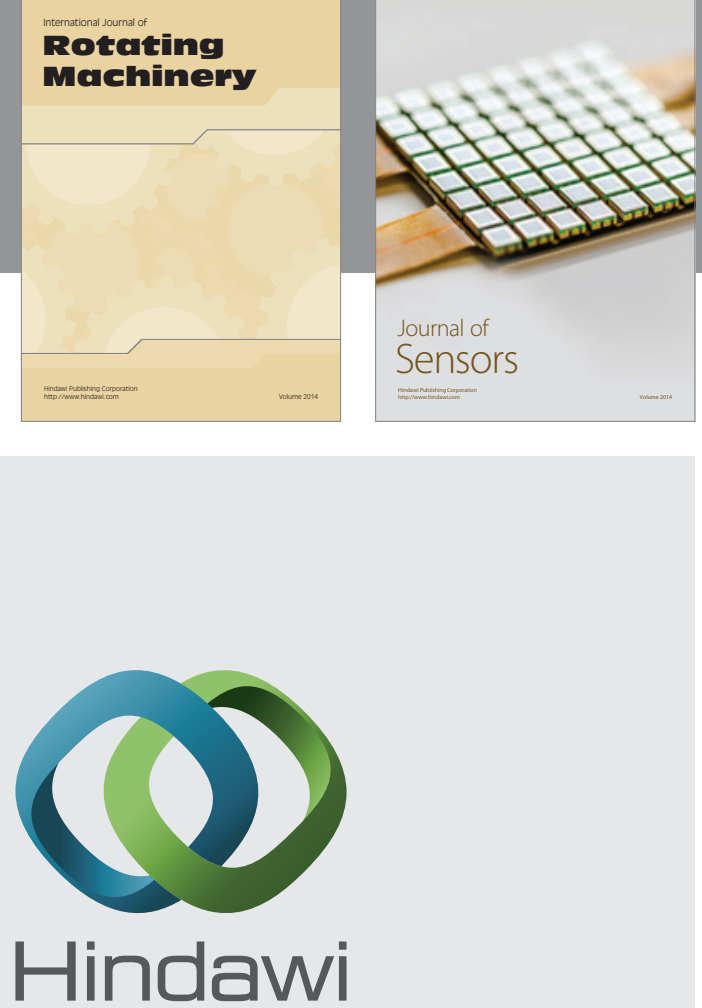

Submit your manuscripts at http://www.hindawi.com
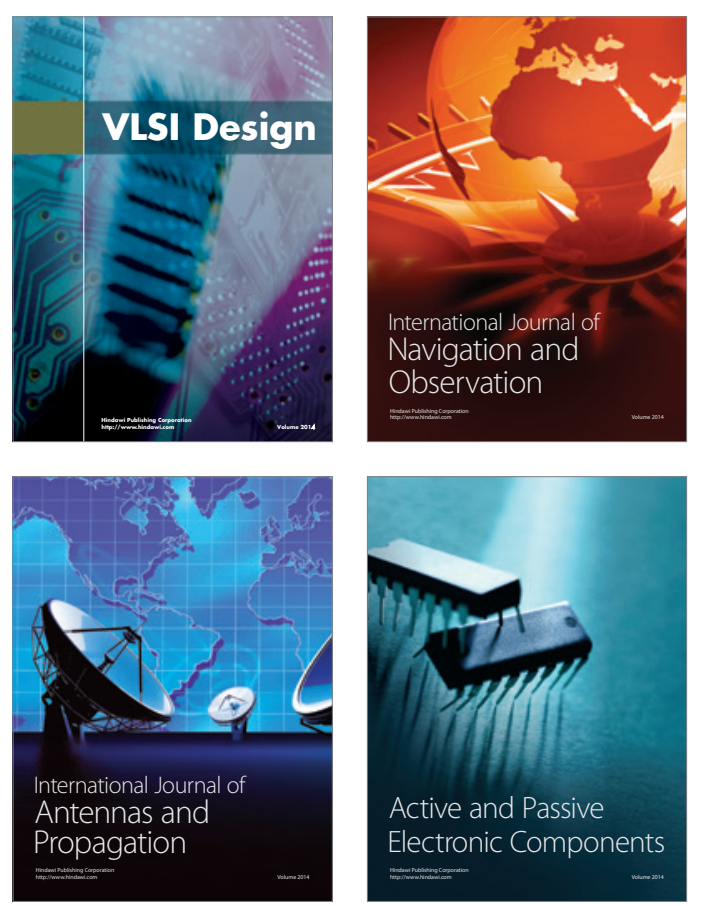
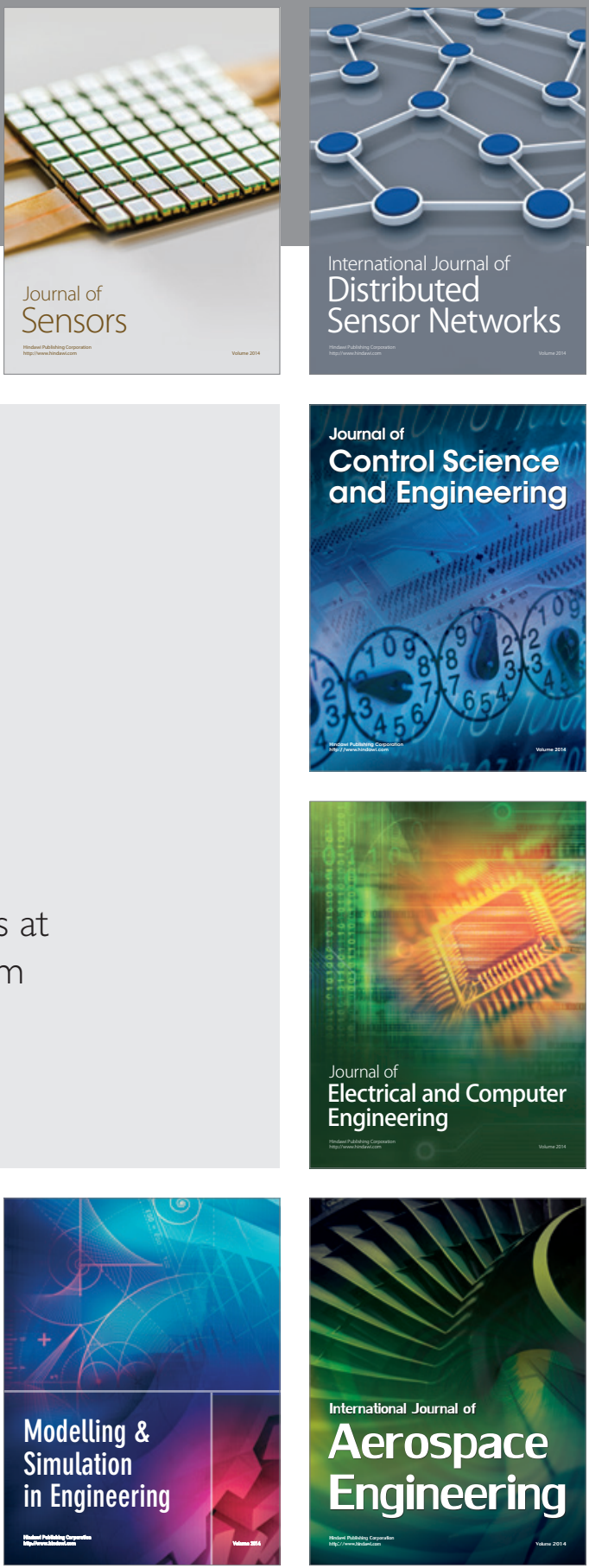

Journal of

Control Science

and Engineering
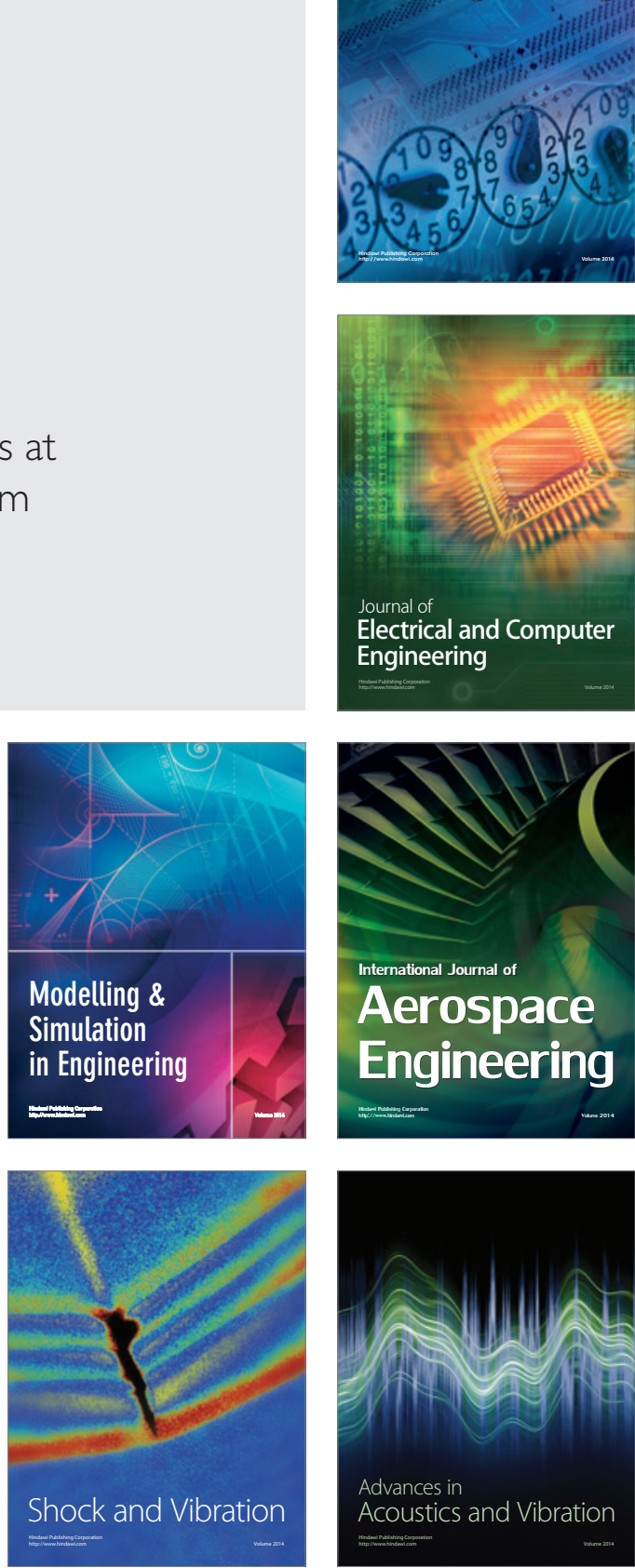